This PDF is a selection from a published volume from the National Bureau of Economic Research

Volume Title: Means-Tested Transfer Programs in the United States

Volume Author/Editor: Robert A. Moffitt, editor

Volume Publisher: University of Chicago Press

Volume ISBN: 0-226-53356-5

Volume URL: http://www.nber.org/books/moff03-1

Conference Date: May 11-12, 2000

Publication Date: January 2003

Title: Child Care Subsidy Programs

Author: David Blau

URL: http://www.nber.org/chapters/c10260 


\title{
Child Care Subsidy Programs
}

\author{
David M. Blau
}

\subsection{Introduction}

Child care and early education subsidies for low-income families make up a relatively small but growing share of the portfolio of government means-tested transfer programs in the United States. The federal and state governments are estimated to have spent at least 18 billion dollars on such subsidies in fiscal year 1999. Many different government programs have provided means-tested child care and early education subsidies. Several of the major programs were consolidated into a single block grant as part of the welfare reform of 1996, but a number of major programs and many minor programs remain separate. Child care and early education subsidies are an important part of public efforts to help low-income families support themselves by work rather than welfare. They are also an important part of efforts to improve child outcomes for low-income families.

Economic analysis of child care subsidies is important for at least four reasons. First, the monetary cost of child care is often cited as a major barrier to economic self-sufficiency for low-income families with young children. Child care subsidies reduce or eliminate this cost of employment, and parental employment is an eligibility requirement for many child care subsidy programs. But there are other approaches to encouraging low-income parents to be employed - for example, the Earned Income Tax Credit. The relative effectiveness of child care subsidies at increasing employment Hill.

David M. Blau is professor of economics at the University of North Carolina at Chapel

The author is grateful to Ronald Oertel for very helpful research assistance. He thanks Susan Averett, Barbara Bergmann, Dan Black, Janet Currie, Jonah Gelbach, Suzanne Helburn, Robert Moffitt, David Ribar, Philip Robins, and James Walker for useful comments. The author is responsible for errors and opinions. 
compared to other possible approaches is an important issue. An economic analysis can clarify the conditions under which a child care subsidy is a relatively effective policy tool for increasing employment of lowincome parents.

Second, the quality of child care in the United States is typically characterized as mediocre on average, particularly in comparison to child care in most European countries. Improving the quality of child care has been an explicit goal of several major child care subsidy programs in the United States. But recent federal child care programs emphasize freedom of choice and flexibility for parents, with few restrictions on the type or characteristics of child care arrangements eligible for subsidies. Economic analysis can demonstrate the conditions under which there is a trade-off in child care policy between increasing employment and improving the quality of care.

Third, early childhood education and intervention programs such as Head Start are intended to help low-income children overcome the developmental disadvantages of growing up in poverty. Such programs have different goals than child care subsidies, but they provide what is in effect subsidized child care of relatively high quality to large numbers of lowincome children. A unified economic analysis of child care and early education subsidies can demonstrate the trade-offs between government expenditures on such programs.

Fourth, the legislation authorizing the major federal welfare reform of 1996 is up for reauthorization in 2002 . The child care subsidy program created by the reform is also up for renewal, and there is considerable sentiment for increasing the level of funding for child care. Economic analysis of the effects of child care subsidies can and should be an important input in the debate over future child care policy.

This chapter describes child care and early education subsidy programs in the United States; discusses the rationale for such programs and the economic issues raised by the existence and structure of the programs; reviews evidence on the effects of the programs on the behavior and outcomes of low-income families; and discusses proposals for reform of such programs. Section 7.2 summarizes the history and rules of the main programs, and section 7.3 tabulates information on expenditures, caseloads, and characteristics of subsidy recipients and child care users. Section 7.4 discusses the economic issues: Why does the government subsidize child care, what are the goals of such subsidies, what are the work incentives of the programs, and what are the incentives provided by the programs with respect to the quality of child care and the well-being of children? Empirical evidence on these issues is discussed in section 7.5, including evidence drawn from experimental demonstrations, evaluations of existing subsidies, and econometric analysis of price effects. Section 7.6 discusses a number of policy issues that have been prominent in recent discussions of child care subsidies 
and describes options for further reform of the child care subsidy system in the United States. Section 7.7 concludes by suggesting fruitful avenues for research.

\subsection{Structure and Recent History of Child Care and Early Education Subsidy Programs}

The programs considered in this chapter provide subsidies for nonparental child care and early education of children in low-income families. Some of the programs subsidize work-related child care expenses only, but others, such as Head Start, have no employment requirement for the parents. The goals and structure of work-related child care subsidy programs are typically quite different from those of early education programs, and it would simplify the discussion if only work-related child care subsidies were considered in this chapter. However, this would neglect an important issue that recurs throughout the chapter: the trade-off faced by policymakers between the goals of improving child well-being and increasing economic self-sufficiency. This trade-off is recognized as a fundamental issue in child care policy, and as such it should be discussed in this chapter. The structure of a subsidy for work-related child care expenses affects the quality of child care purchased, whether or not this is a goal of the subsidy program; and the structure of an early education program affects the work incentives of the parents, whether by design or not. Tax deductions and credits that provide unrestricted child subsidies (subsidies based on the presence of children that are not restricted in how parents can spend the funds) are not discussed in this chapter, although the related issue of "child allowances" is included in the discussion of reform options in section 7.6. The one major child care subsidy program not discussed here is the exclusion from taxable income of employer-provided dependent care expenses, because it is not means tested. ${ }^{1}$

The history, goals, and main provisions of the major child care and early education programs considered in this chapter are summarized in table 7.1. ${ }^{2}$ The subsidy rate in the Dependent Care Tax Credit (DCTC) declines with the level of income, so this program is means tested in a sense, although the subsidy rate remains constant for Adjusted Gross Income (AGI) above $\$ 28,000$. More importantly, because the credit is not refundable the amount of credit available to low-income families is relatively small. A nonrefundable credit is limited to the amount of income tax lia-

1. See U.S. House of Representatives, Committee on Ways and Means (1998, 838-39) for a description of this program. Another non-means-tested program not considered is military child care (U.S. General Accounting Office 1999a).

2. Some smaller programs omitted from the table are listed in U.S. General Accounting Office (1994b) and Robins (1991). A number of states have their own tax credits for child care, but they generally provide small benefits. 


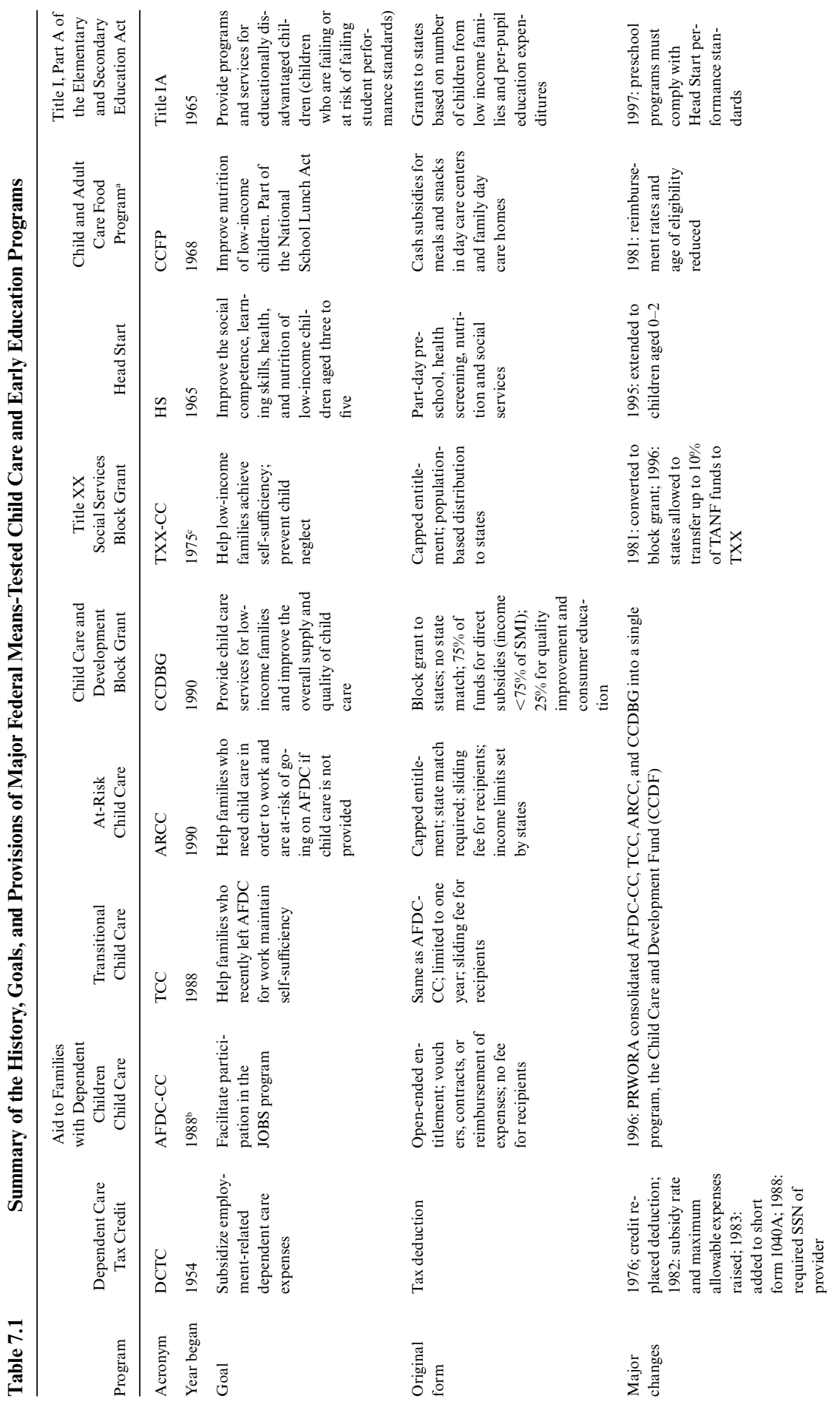




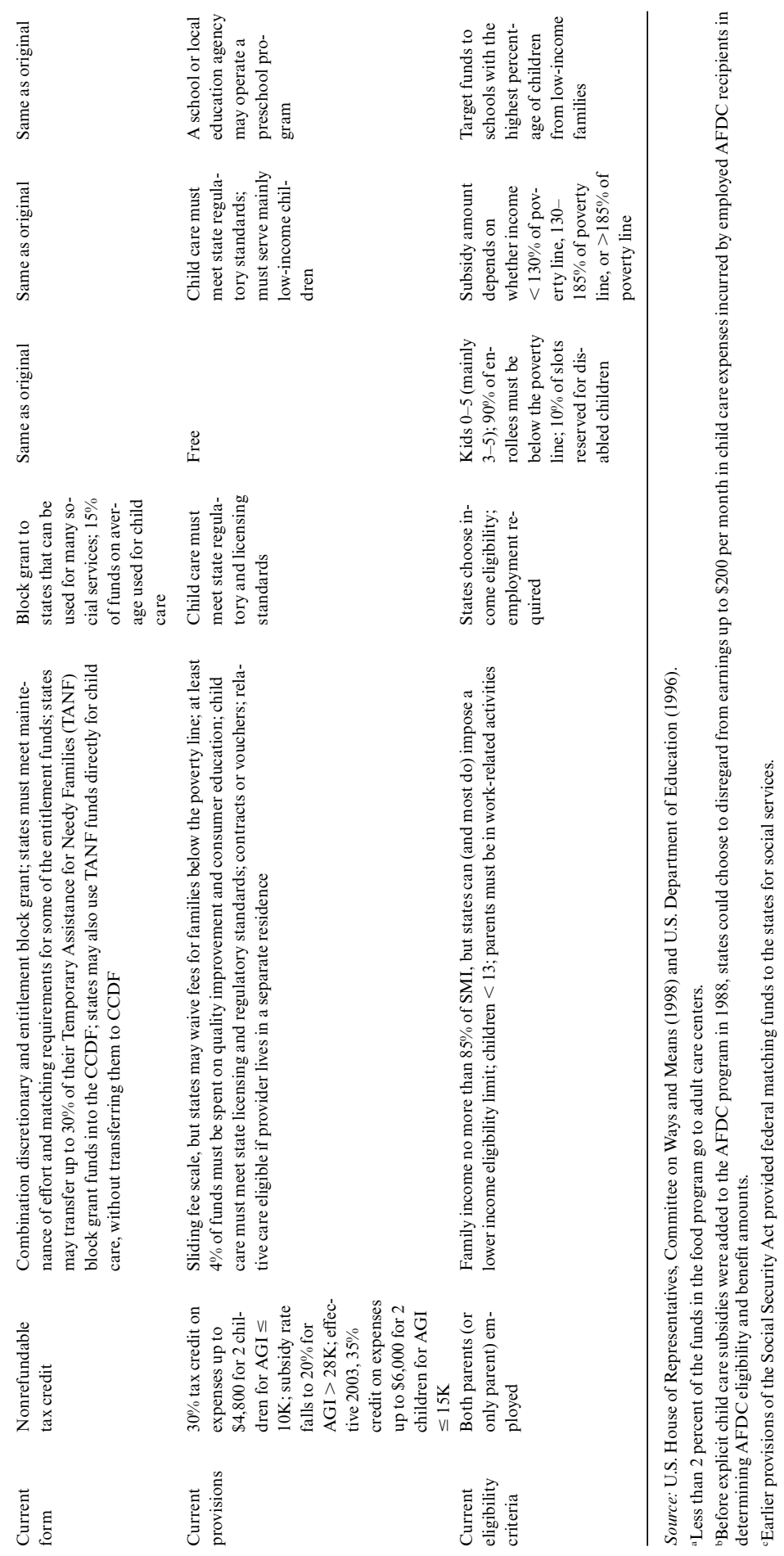


bility; many low-income families have no federal income tax liability and therefore cannot receive any tax credit. Data from the Internal Revenue Service indicate that 20.8 percent of the total amount of tax credit claimed in 1999 went to families with AGI of less than $\$ 30,000$, but almost all of this amount was claimed by families with AGI between $\$ 15,000$ and $\$ 30,000$; only 0.7 percent of the total was claimed by families with AGI less than $\$ 15,000 .^{3}$ As noted in table 7.1, the DCTC is scheduled to become more generous in 2003, with the maximum subsidy rate increasing from 30 to 35 percent, the income limit for the maximum subsidy rate increasing from $\$ 10,000$ to $\$ 15,000$, and allowable expenses increasing form $\$ 4,800$ to $\$ 6,000$ for two children.

The 1988 Family Support Act (FSA) mandated two new programs, Aid to Families with Dependent Children Child Care (AFDC-CC) and Transitional Child Care (TCC). The AFDC-CC subsidy was intended to facilitate participation of welfare recipients in the Job Opportunities and Basic Skills (JOBS) program, an employment/training program mandated by the FSA to move families off welfare to economic self-sufficiency. The goal of the TCC program was to help maintain employment by providing subsidies to families who had recently moved off welfare, for up to one year after leaving welfare. The Omnibus Budget and Reconciliation Act (OBRA) of 1990 introduced two more new programs, At-Risk Child Care (ARCC) and the Child Care and Development Block Grant (CCDBG). The ARCC program provided child care subsidies to families who might otherwise not have been able to work and would as a result be at risk of going on welfare. The CCDBG had two goals: to provide more funds to subsidize employment-related child care expenses for low-income families, and to subsidize quality-improvement activities and consumer education. The qualityimprovement activities that could be subsidized included resource and referral services, grants to providers to enable them to meet state child care regulations, improvements in monitoring and enforcement of regulations, and training programs for staff.

The proliferation of programs with different target populations, eligibility requirements, and subsidy rates following the passage of FSA and OBRA led to a fragmented system in which families would have to switch from one program to another as a result of changes in employment and welfare status, and some families would not be eligible for any subsidy despite having economic circumstances quite similar to those of eligible families. Examples of the consequences of this fragmentation are given in U.S.

3. Internal Revenue Service (2001). 31.2 percent of returns filed in 1999 had AGI of less than $\$ 15,000$, but the number of these with children is unknown. Thirty-eight percent of returns with AGI under $\$ 15,000$ owed income tax. In 1999, single household heads with gross income of at least $\$ 9,100$ and married households with income of at least $\$ 12,700$ were required to file a tax return. The number of low-income households that did not file a return is unknown. 
Advisory Commission on Intergovernmental Relations (1994), U.S. General Accounting Office (1995), Ross (1996), and Long et al. (1998). For example, Long et al. (1998, 6-7) note that prior to welfare reform in California and Massachusetts the various child care programs were administered by different state agencies. Families had to apply separately for each of the programs and could incur significant time and hassle costs in changing from one program to another as a result of a change in family income or age of the child. ${ }^{4}$

In 1996 the Personal Responsibility and Work Opportunity Reconciliation Act (PRWORA) consolidated the four programs created by FSA and OBRA into a single child care block grant program called the Child Care and Development Fund (CCDF). ${ }^{5}$ The main goal of the consolidated program is to facilitate the transition from welfare to work and help maintain employment of low-income parents. A minimum of 4 percent of funds must be used by states for quality-improvement and consumer education activities. Federal CCDF funds are provided to the states in three "streams": discretionary, mandatory, and matching. Discretionary and mandatory funds are distributed according to rules similar to those of the old programs, primarily based on the number of children and state income. These two streams do not require state matching funds. To receive funds from the matching stream, "a state must maintain its expenditure of state funds for child care programs at specified previous levels ('maintenanceof-effort' spending) and spend additional state funds above those levels" (U.S. General Accounting Office 1998, p. 5). One of the main goals of the consolidation of the four programs was to eliminate the fragmentation that existed under the previous system. Under the new system, states can (but are not required to) allow a family that moves from welfare to work to continue receiving a child care subsidy without changing programs. According to Long et al. (1998), states have made considerable progress in creating more seamless child care subsidy programs since the passage of PRWORA,

4. Most of the discussion of child care cost in this chapter refers to the monetary cost of care. There are other costs as well, such as the cost of establishing and maintaining eligibility for a subsidy, searching for care, arranging for substitute care when the regular provider is not available, and the disutility associated with using nonparental care. These nonmonetary costs are difficult to measure but may be quite important. The models described in section 7.4.2 incorporate a general form of nonmonetary child care cost.

5. Three of the previous programs (AFDC-CC, TCC, and ARCC) were authorized and funded by Social Security Title IV-A. They were replaced by the Temporary Assistance for Needy Families (TANF) Child Care Block Grant, funded by the Social Security Act. PRWORA also reauthorized and revised the existing CCDBG program with its own funding. Finally, it stipulated that both the new TANF Child Care Block Grant and the CCDBG be administered by the CCDBG program. The combined program is called the CCDF, and it consists of the two separately authorized funding streams, administered jointly and subject to the same rules (Pitegoff and Bream 1997). Many documents continue to refer to the joint program as the CCDGB, but the correct name of the combined program is now the CCDF. Most of the information on the CCDF provided here is from the Final Rule issued by U.S. Department of Health and Human Services (1998). 
including single points of entry to the program, unified waiting lists, and consolidation of programs in a single agency (see also Adams, Snyder, and Sandfort 2002).

States can use CCDF funds to assist families with income up to 85 percent of state median income (SMI) but are free to use a lower incomeeligibility criterion. Parents must be employed, in training, or in school, although some exceptions are permitted. In general, priority for CCDF funds is supposed to be given to families with very low incomes and children with special needs. Specifically, states must use at least 70 percent of their mandatory and matching funds to serve families on welfare, families in work activities who are moving off welfare, and families at risk of going on welfare. These correspond to the three groups previously served by the AFDC-CC, TCC, and ARCC programs, respectively. The CCDF also requires that a substantial portion of the discretionary funds and the other 30 percent of mandatory and matching funds be used to assist working poor families who are not current, recent, or likely future welfare recipients - the group previously served mainly by the CCDBG program. As part of the general increase in flexibility provided by PRWORA, states are permitted to transfer up to 30 percent of their TANF block grant funds to the CCDF to be used for child care, and they can also use TANF funds directly for child care services without transferring the funds to CCDF. States must use "certificates" (formerly called vouchers) that allow families to purchase care from any provider that meets state regulations and licensing standards or is legally exempt from licensing, including relatives (who do not live in the child's household) and babysitters. The regulations that govern health, safety, group size, training, and so forth are determined entirely at the state level with no federal requirements, and they vary widely across states. ${ }^{6}$ States are permitted to impose more stringent requirements for child care services funded by CCDF, but any such additional requirements must be consistent with the strong provisions of the CCDF requiring flexibility in parental choice of child care (see U.S. Department of Health and Human Services 1998, p. 39986). States can also contract to purchase slots in day care centers and family day care homes and provide such slots to eligible families.

The other main subsidy program with an employment focus is the Title XX Social Services Block Grant (TXX). This program subsidizes a wide variety of social services and gives states flexibility in how the funds are allocated across the various eligible services. On average, about 15 percent of TXX funds have been spent on child care in recent years (U.S. House of Representatives, Committee on Ways and Means 1998, 720). Child care funded by Title XX must meet applicable state standards, and it is often

6. See the National Child Care Information Center (http://nccic.org) for information on state child care regulations. 
provided through "slots" in centers and family day care homes purchased through grants and contracts with state or local agencies.

The last three programs listed in table 7.1, Head Start, the Child Care and Adult Food Program (CCFP), and Title I-A, are intended to improve child well-being, and these programs therefore have no employment or training requirement for the parents. Head Start programs must meet a set of federal standards that are more stringent and child development-oriented than most state regulations, and Title I-A programs must meet the Head Start standards as well. Head Start also requires parental involvement and provides nutrition and health services as well as early education. The CCFP provides subsidies for meals meeting federal nutrition requirements served in licensed day care centers and family day care homes serving low-income children. Subsidy rates depend on family income of the children served, with a maximum income of 185 percent of the poverty level. Most Title I-A funds go to schools serving K-12 students, but state and local education agencies may use such funds to serve preschool age children as well, in school-based or community-based programs.

\subsection{Program Statistics}

\subsubsection{Expenditures, Caseloads, and Program Rules}

Table 7.2 summarizes federal and state expenditures on child care subsidies in recent years and the numbers of children served by the subsidy programs. Assuming that 25 percent of DCTC expenditures went to lowincome families and that fiscal year (FY) 1999 CCFP expenditures were the same as in FY 2000, a rough figure for total expenditure on means-tested child care subsidies in FY 1999 is $\$ 18$ billion. A meaningful total for the number of children cannot be computed, because the DCTC lists only the number of families served, data are not available for TXX and Title I-A, and some children may be served by more than one program (for example, the DCTC and the CCFP). The CCDF is the biggest program in terms of expenditure, at about $\$ 9$ billion. Much of the CCDF funding was transferred from TANF; the CCDF appropriation for 1999 was $\$ 5.285$ billion. Head Start is the second largest program, with expenditure of $\$ 4.7$ billion in 1999 , $\$ 5.3$ billion in 2000, and $\$ 6.2$ in 2001 . Head Start is the best-funded program per child served, with annual expenditure of $\$ 5,688$ per child versus $\$ 5,189$ per child in the CCDF, and a maximum of $\$ 720$ per child in the DCTC.

The provisions of the DCTC, Head Start, the CCFP, and the Title I-A programs are determined at the federal level, with little discretion given to states. The main provisions of these programs are summarized in table 7.1. In contrast, states have substantial flexibility in designing their CCDF programs, including the income eligibility limit, copayments by families, and reimbursement rates to providers. These rules are summarized for each 


\begin{tabular}{|c|c|c|c|c|c|c|}
\hline & DCTC & HS & TXX-CC & CCFP & $\mathrm{CCDF}$ & Title I-A \\
\hline \multicolumn{7}{|c|}{ Federal + State Expenditures (billions of current dollars) } \\
\hline FY 2001 & & 6.200 & & & & \\
\hline FY 2002 & & 5.267 & 0.231 & 1.559 & & \\
\hline FY 1999 & 2.675 & 4.968 & 0.285 & & 9.132 & 2.015 \\
\hline FY 1998 & 2.649 & 4.347 & & & 6.399 & \\
\hline FY 1997 & 2.464 & 3.981 & 0.370 & 1.524 & 4.369 & \\
\hline FY 1996 & 2.663 & 3.569 & 0.352 & 1.580 & & \\
\hline FY 1995 & 2.518 & 3.534 & 0.414 & 1.467 & 3.100 & \\
\hline \multicolumn{7}{|c|}{ Children Served (millions) } \\
\hline FY 2001 & & 0.905 & & & & \\
\hline FY 2000 & & 0.857 & & & & \\
\hline FY 1999 & 6.182 & 0.826 & & & 1.760 & \\
\hline FY 1998 & 6.120 & 0.822 & & 2.6 & 1.515 & \\
\hline FY 1997 & 5.796 & 0.794 & & 2.2 & 1.248 & \\
\hline FY 1996 & 6.003 & 0.752 & & 2.4 & & \\
\hline FY 1995 & 5.964 & 0.751 & & 2.3 & 1.445 & \\
\hline
\end{tabular}

Sources: Dependent Care Tax Credit (DCTC): U.S. House of Representatives, Committee on Ways and Means $(2000,816)$, except 1999: Internal Revenue Service (2001). Figures in the lower panel are number of returns filed claiming the credit, not the number of children. Head Start (HS): Administration for Children and Families (2002). Title XX Child Care (TXXCC): Committee on Ways and Means (2000, pp. 600, 634): 15 percent of $\$ 1.9$ billion for 1999; 13 percent of $\$ 1.775$ billion for 2000; Committee on Ways and Means $(1998$, pp. 714, 720): 14.8 percent of $\$ 2.800, \$ 2.381$, \$2.500 for FY 1995, 1996, 1997. Child Care Food Program (CCFP): expenditure: Committee on Ways and Means (2000, 600); Committee on Ways and Means (1998, pp. 714, 720); children served: U.S. Department of Agriculture (2001). Child Care and Development Fund (CCDF): Expenditure: 1997-99: I computed expenditure figures by summing all federal and state expenditures on the CCDF, either directly or through transfers to TANF, using data from the Annual TANF Reports to Congress (U.S. Department of Health and Human Services, various years) and reports from the Administration for Children and Families (various years). The latter source provides allocations to the CCDF for FY 2000 and 2001, but there are no data available on transfers from TANF for these years. Transfers to TANF constituted about half of CCDF spending in FY 1999. 1995: U.S. General Accounting Office $(1998,4)$; total funding for the four programs later consolidated in to the CCDF: AFDC-CC, TCC, ARCC, CCDBG. Children served: 1999: Administration for Children and Families (2000); 1998: Administration for Children and Families (2001b); 1997: Administration for Children and Families (1998); 1995: Administration for Children and Families (1995). Title I-A: U.S. General Accounting Office (1999b, 6): Department of Education programs: Title I part A, Individuals with Disabilities Education Act, Even Start, Twenty-First Century Learning Centers. U.S. General Accounting Office (2000) gives different figures and an estimate of 341,000 preschool children served by Title I-A and Even Start. Notes: See table 7.1 for definition of the program acronyms. Expenditures are given in current dollars to facilitate checking with the original sources. To convert expenditures to 2001 dollars using the Consumer Price Index, multiply dollar figures for 1995-2000 by 1.162, 1.129, $1.103,1.0865,1.063$, and 1.028 , respectively. Blank cells indicate data not available. 
state in table 7.3. Only nine states set income eligibility at the maximum allowed by law, 85 percent of SMI. Ten states set the income eligibility limit at less than 50 percent of SMI. States are permitted to waive fees (copayments) for families with income below the poverty line, and the fourth column of table 7.3 shows that there is substantial variation across states in use of this provision. Fees are determined in many different ways, including flat rates, percent of cost, percent of income, and combinations of these. States are required to have sliding scale fee structures, with fees that rise with family income. The minimum fee shown in the fifth column of the table is the copayment required of the lowest-income families, and the maximum fee shown in the sixth column is the copayment for the highestincome eligible families. The reimbursement rates listed in the last two columns represent the amount of the subsidy exclusive of the family copayment. States that provide relatively generous reimbursement also tend to have higher income eligibility limits: The correlation between the figures in columns (2) and (8) is .51, and between the figures in columns (3) and (8) is .25. Federal guidelines for implementation of the CCDF law require that the subsidy rate be set at the 75th percentile of the price distribution from a recent local market rate survey. In practice many states use out-of-date market rate surveys or set the subsidy rate lower than the 75th percentile of the price distribution (Adams, Schulman, and Ebb 1998, 23). There are no systematic data available on the difference between reimbursement rates and fees actually charged by providers. Anecdotal evidence compiled by the Children's Defense Fund indicates that "In many states, child care subsidy rates are so low that many providers are unwilling to accept children who have subsidies or limit the number of children with subsidies they are willing to accept. Some providers may take subsidies, but only if parents pay them the difference between what the subsidy rate will cover and the provider's actual rate (in addition to the copayment the parent is already required to pay)" (Adams, Schulman, and Ebb 1998, 20). This is inconsistent with the requirement of the CCDF that payment rates should be sufficient to ensure equal access for CCDF-eligible children to comparable child care services provided to children not eligible for child care assistance (U.S. Department of Health and Human Services 1998, p. 39985).

The only subsidy program that is an open-ended entitlement is the DCTC (in terms of number of children served, not expenditures per child), and as explained above this is one of the smaller low-income child care subsidy programs. The other programs are capped entitlements, with no obligation to serve all eligible families. It is estimated that the CCDF serves only 15 percent of eligible children (Administration for Children and Families, 1999). ${ }^{7}$ There is no systematic information available on how CCDF

7. Many families who are eligible do not apply for a subsidy from the CCDF. See Besharov (2002) for a discussion of the possible reasons for low take-up of the subsidy. 


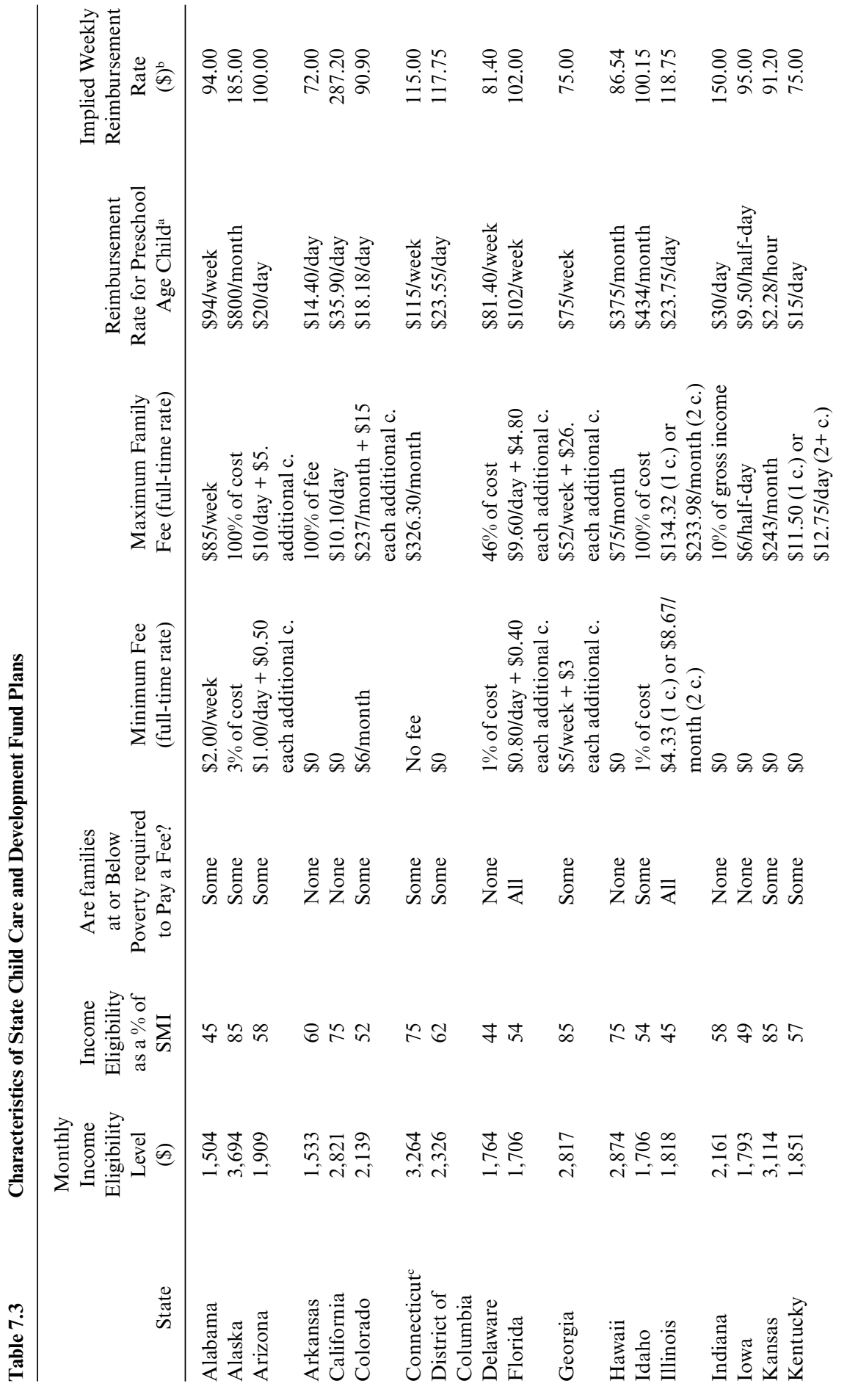




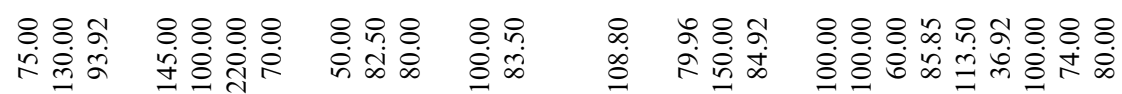

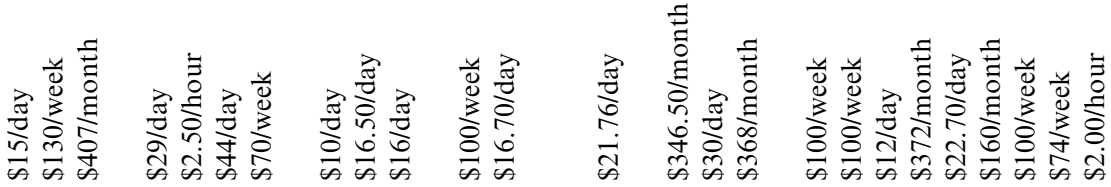

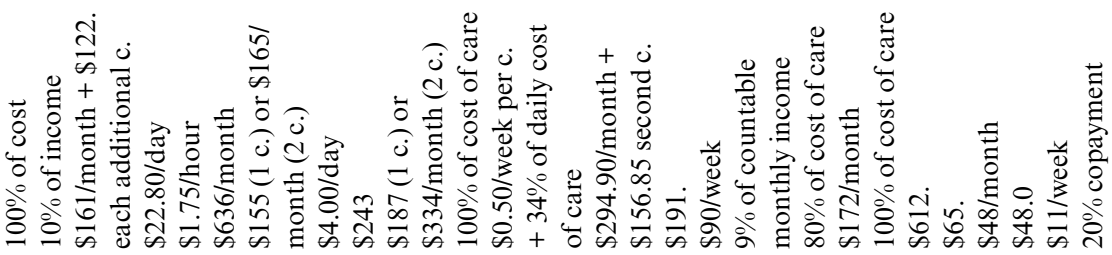

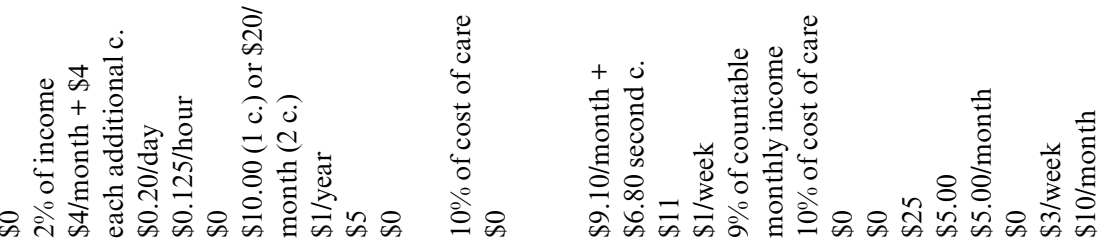

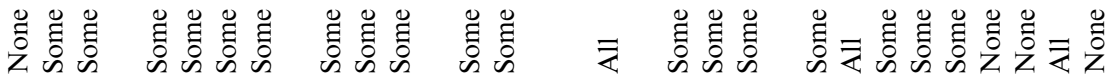
상

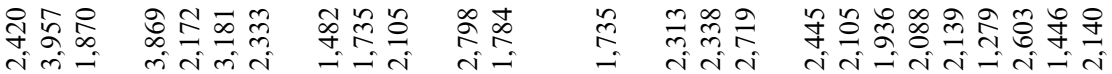

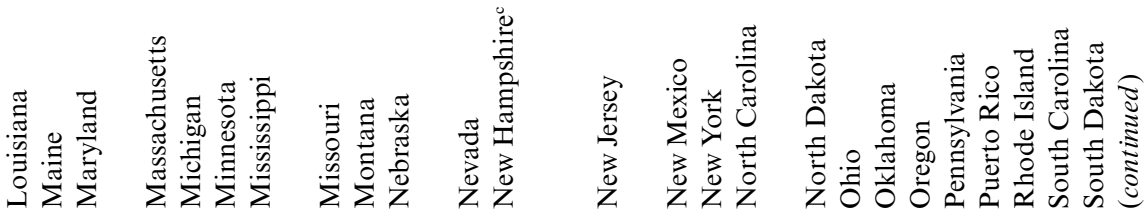




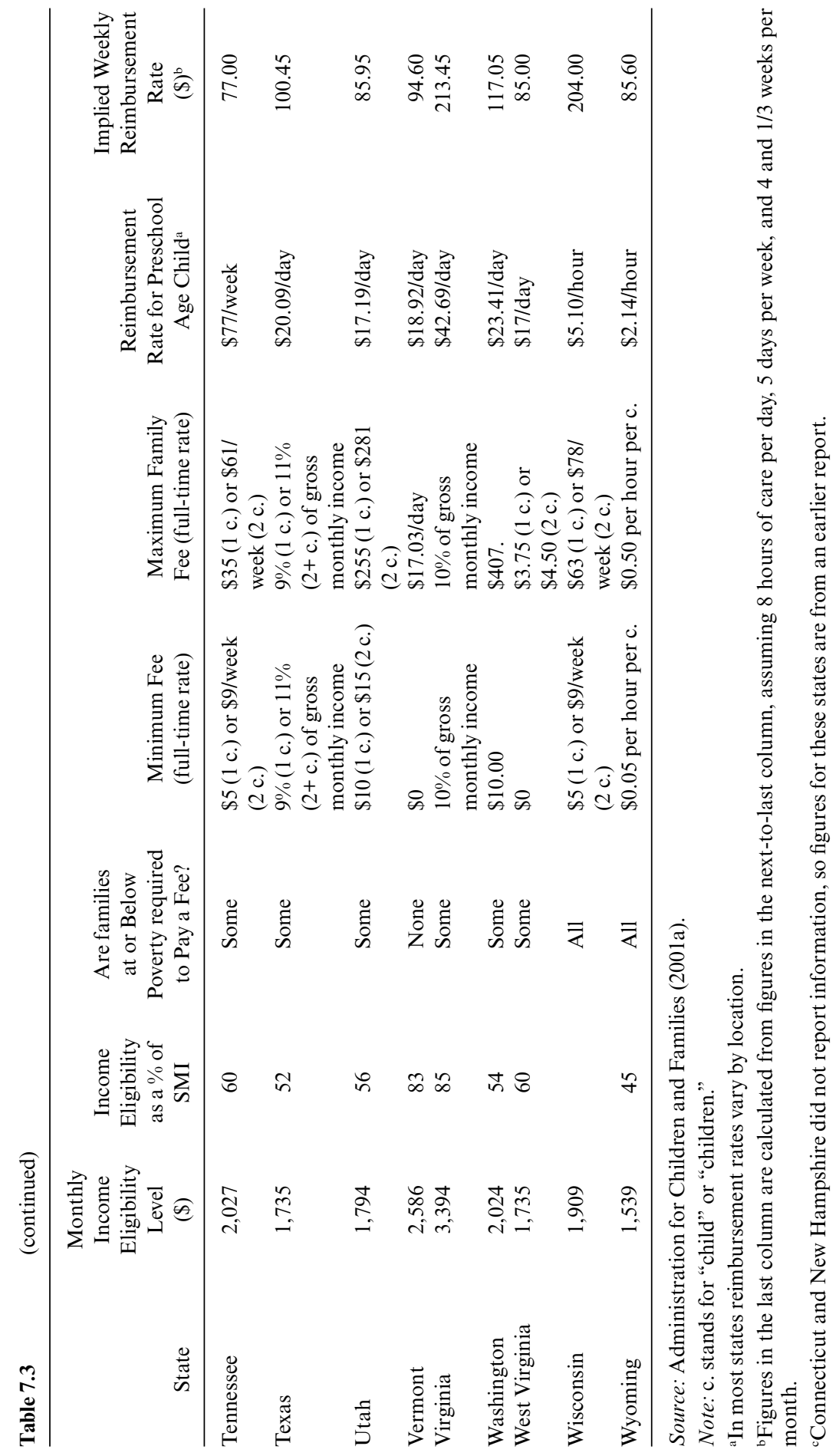


funds are allocated among eligible families. Head Start served 822,316 children in FY 1998, compared to 4.775 million children under age six in poverty in calendar year 1998 (U.S. Bureau of the Census 1999, table 2). However, 89 percent of children in Head Start are aged three to four. ${ }^{8}$ Assuming that one-third of the children under age six are ages three to four yields about 50 percent of three-to-four-year-old children in poverty who are served by Head Start (see Currie 2001 for a similar estimate). No figures are available on the percentage of eligible children served by the other programs.

Family income is a determinant of eligibility in all of the programs listed in table 7.1 except for the DCTC, and in several of the programs income determines the subsidy rate or amount (DCTC, CCDF, CCFP). If cash or inkind benefits from other means-tested programs were counted as part of income for determining eligibility and/or benefits from child care subsidy programs, there would be important interactions between child care programs and other means-tested subsidy programs. States are given discretion in determining which sources of income are counted in determining CCDF eligibility. All states include earned income (a few disregard a small share of earnings), the majority include TANF and child support income, and almost all exclude food stamps and EITC from the income definition (Ross 2002).

\subsubsection{Recipient Characteristics}

The Survey of Income and Program Participation (SIPP) panel of 1996 collected information about child care subsidies from a sample of households with at least one child under age fifteen in spring 1999. Respondents were asked "Did anyone help you pay for all or part of the cost of any child care arrangements for the child?" Respondents who replied affirmatively were asked whether the source of the assistance was a government agency. In another section of the survey respondents were asked if any of their children were enrolled in Head Start. Many respondents who reported having a child enrolled in Head Start did not report receiving a subsidy, so I reclassified them as receiving a subsidy. The tabulations reported in Panel A of table 7.4 show that only 2.1 percent of the sample reported receiving a government subsidy. This could be a substantial underestimate of subsidy receipt if respondents did not include arrangements that were subsidized by tax credits or direct government reimbursement to the provider through grants and contracts, which remains a common form of subsidy in several means-tested programs. The incidence of receipt of a subsidy was 4.0 percent for the lowest income group and 11.2 percent for families who were public assistance recipients.

8. An "Early Head Start" program was authorized in 1994 to serve children below age three. It is a small part of the overall Head Start program. 


\begin{tabular}{|c|c|c|c|c|c|}
\hline & \multirow{2}{*}{$\begin{array}{l}\text { Proportion } \\
\text { with } \\
\text { Subsidy }\end{array}$} & \multicolumn{2}{|c|}{$\begin{array}{c}\text { Receives } \\
\text { Public Assistance }\end{array}$} & \multicolumn{2}{|c|}{$\begin{array}{l}\text { Does Not Receive } \\
\text { Public Assistance }\end{array}$} \\
\hline & & Subsidy & $\begin{array}{c}\text { No } \\
\text { Subsidy }\end{array}$ & Subsidy & $\begin{array}{l}\text { No } \\
\text { Subsidy }\end{array}$ \\
\hline \multicolumn{6}{|c|}{ A. Incidence } \\
\hline \multicolumn{6}{|c|}{ Annual household income $(\$ 000)$} \\
\hline All & .021 & & & & \\
\hline $0-4.99$ & .040 & & & & \\
\hline $5.00-9.99$ & .053 & & & & \\
\hline $10.00-14.99$ & .042 & & & & \\
\hline $15.00-19.99$ & .029 & & & & \\
\hline $20.00-24.99$ & .033 & & & & \\
\hline $25.00-29.99$ & .025 & & & & \\
\hline $30.00-34.99$ & .029 & & & & \\
\hline $35.00-39.99$ & .013 & & & & \\
\hline $40.00+$ & .009 & & & & \\
\hline \multicolumn{6}{|l|}{ Public assistance (PA) status } \\
\hline Receives PA & .112 & & & & \\
\hline Does not receive PA & .022 & & & & \\
\hline \multicolumn{6}{|c|}{ B. Characteristics of households with annual income $<\$ 25,000$} \\
\hline Center & & .45 & .05 & .41 & .05 \\
\hline Nonrelative & & .44 & .10 & .33 & .11 \\
\hline Other nonparent & & .10 & .31 & .20 & .30 \\
\hline Pay for care & & .42 & .10 & .46 & .14 \\
\hline Cost/hour & & 2.55 & 1.76 & 2.81 & 3.07 \\
\hline Mother employed & & .61 & .28 & .79 & .49 \\
\hline Hours worked (if $>0$ ) & & 39 & 33 & 37 & 37 \\
\hline Wage rate & & 6.62 & 6.58 & 6.71 & 7.10 \\
\hline Education $>12$ & & .45 & .18 & .52 & .32 \\
\hline Married, spouse present & & .12 & .12 & .35 & .51 \\
\hline Annual earnings (if $>\$ 0$ ) & & $\$ 10,760$ & $\$ 7,575$ & $\$ 11,053$ & $\$ 11,953$ \\
\hline Other adults & & .09 & .28 & .17 & .21 \\
\hline Fewer than five children & & 1.09 & .72 & .84 & .68 \\
\hline Black & & .34 & .40 & .28 & .21 \\
\hline Hispanic & & .23 & .29 & .17 & .24 \\
\hline White & & .43 & .25 & .52 & .50 \\
\hline$N$ & 15,747 & 89 & 762 & 88 & 3,875 \\
\hline
\end{tabular}

Source: Tabulations from the Survey of Income and Program Participation (spring 1999).

Notes: Unit of analysis is one child. Figures are weighted by the child's sample weight. A child is coded as receiving a subsidy if the mother reports that a government agency helps pay for child care or that one of the child's arrangements is Head Start. Public assistance includes cash (TANF, GA, SSI) and food stamps. Center care includes nursery, preschool, and Head Start. Nonrelative includes family day care homes, nannies, babysitters, and other nonrelatives (except centers). 
Panel B of table 7.4 restricts the sample to households with annual income under $\$ 25,000$ and classifies them by whether they received public assistance and whether they received a child care subsidy. Subsidy recipients were much more likely to use a day care center than nonrecipients (this is true even if Head Start cases are excluded). This may reflect the fact that direct provider reimbursement is used mainly for day care centers. The mother was much more likely to be employed in households receiving a subsidy. This is a major change from ten years earlier, and it is consistent with the post-PRWORA emphasis on employment for welfare recipients. In the welfare group, subsidy recipients had higher average earnings and hours of work, and wages similar to those of nonrecipients. In the nonwelfare group, subsidy recipients had a lower wage, similar hours per week, and higher annual earnings than nonrecipients. ${ }^{9}$ Some important questions about subsidies that cannot be answered based on these data are what fraction of nonrecipients were ineligible, what fraction of eligible families were aware of their eligibility, what fraction of those who were aware applied for a subsidy, and what fraction of applicants were awarded a subsidy. Information from site-specific surveys suggests that lack of awareness of subsidies among eligible families is widespread (Meyers and Heintze 1999; Fuller et al. 2000).

The only other information available on characteristics of child care subsidy recipients is fragmentary. Piecyk, Collins, and Kreader (1999) used data from administrative records in Illinois and Maryland for 1997 and 1998 to tabulate characteristics of children and families whose child care was subsidized by a voucher and who were current or former cash assistance recipients. Of those children who were current or recent welfare recipients and were receiving subsidized child care from a voucher, roughly half were current welfare recipients and half former recipients. Maryland subsidy recipients were much more likely to use center and family day care than Illinois voucher recipients. Voucher use increased substantially during 1997, and there was also a substantial amount of turnover in the voucher programs. ${ }^{10}$

9. An earlier study, the 1990 National Child Care Survey (NCCS), asked respondents whether they planned to claim a tax credit for child care expenses for 1989. Twenty-eight percent of respondents with family income under $\$ 25,000$ planned to claim a credit, compared to 35 percent of families with income above this threshold. These figures cannot be compared to IRS data because the population covered in the NCCS includes only families with children under thirteen, and the IRS does not report the number of tax returns by age of children. Among the lower-income group in the NCCS, claimants had higher wages and earnings and were less likely to be married, Hispanic, and white than nonclaimants.

10. For additional information on characteristics of subsidy recipients in site-specific studies, see Schumacher and Greenberg (1999) and Fuller, Kagan, and Loeb (2002). Chipty et al. (1998), Fuller et al. (1999) and Meyers and Heintze (1999) use samples of low-income mothers to examine child care subsidy issues but do not report characteristics of subsidy recipients separately from other groups. 


\subsubsection{Types of Child Care and Payment for Care}

An important feature of the child care market is the diversity of types of child care used. Table 7.5 shows the distribution of primary child care arrangements of children under age six of employed mothers in Spring 1999, using data from SIPP. In almost half of all primary child care arrangements for young children of employed mothers, the caregiver is the mother, the father, or another relative. About 30 percent of arrangements are in day care centers or preschools, 11 percent in family day care homes, and 9 percent in other nonrelative arrangements such as a babysitter or nanny. These figures are quite similar to the distribution in the Urban Institute's 1997 National Survey of America's Families (Capizzano, Adams,

Table 7.5 Distribution of Children under Age Six of Employed Mothers by Primary Child Care Arrangement in the Survey of Income and Program Participation, Spring 1999

\begin{tabular}{|c|c|c|c|c|c|c|}
\hline & Father & $\begin{array}{l}\text { Other } \\
\text { Relative }\end{array}$ & $\begin{array}{l}\text { Mother, } \\
\text { while } \\
\text { at work }\end{array}$ & $\begin{array}{c}\text { Other } \\
\text { Nonrelative }\end{array}$ & $\begin{array}{c}\text { Family } \\
\text { Day Care } \\
\text { Home }\end{array}$ & $\begin{array}{l}\text { Center or } \\
\text { Preschool }\end{array}$ \\
\hline All & 17.1 & 28.4 & 3.0 & 9.5 & 11.1 & 30.9 \\
\hline White & 18.4 & 23.4 & 3.3 & 9.3 & 13.8 & 31.8 \\
\hline Black & 11.2 & 34.7 & 1.8 & 8.2 & 5.2 & 39.0 \\
\hline Hispanic & 17.5 & 39.6 & 3.0 & 12.7 & 7.2 & 19.8 \\
\hline Married & 20.3 & 24.0 & 3.5 & 9.7 & 11.7 & 30.6 \\
\hline $\begin{array}{c}\text { Widowed, divorced, } \\
\text { or separated }\end{array}$ & 7.9 & 32.4 & 2.9 & 7.5 & 12.4 & 37.0 \\
\hline Never married & 9.8 & 43.1 & 1.2 & 9.9 & 8.0 & 23.7 \\
\hline \multicolumn{7}{|l|}{ Child age } \\
\hline 0 & 24.3 & 33.1 & 3.0 & 9.4 & 11.0 & 17.1 \\
\hline 1 & 19.1 & 31.6 & 3.1 & 13.5 & 13.6 & 19.1 \\
\hline 2 & 17.4 & 30.1 & 5.4 & 10.5 & 12.5 & 24.2 \\
\hline 3 & 18.0 & 33.3 & 2.1 & 7.9 & 12.0 & 26.8 \\
\hline 4 & 12.9 & 24.7 & 1.6 & 8.7 & 10.4 & 41.8 \\
\hline 5 & 13.4 & 19.1 & 1.7 & 7.2 & 7.4 & 51.4 \\
\hline Full-time & 13.4 & 28.4 & 1.9 & 10.1 & 13.1 & 33.2 \\
\hline Part-time & 25.5 & 28.9 & 5.0 & 8.4 & 7.8 & 24.5 \\
\hline Day shift & 12.3 & 26.9 & 2.9 & 9.3 & 13.2 & 35.3 \\
\hline Nonday shift & 30.1 & 32.4 & 3.3 & 10.0 & 5.4 & 19.0 \\
\hline \multicolumn{7}{|c|}{$\begin{array}{l}\text { Annual family income } \\
\qquad(\$ 000)\end{array}$} \\
\hline$<18.00$ & 14.2 & 34.0 & 1.0 & 10.0 & 8.8 & 30.2 \\
\hline $18.00-35.99$ & 20.9 & 35.6 & 2.7 & 8.2 & 8.1 & 24.5 \\
\hline $36.00-53.99$ & 18.8 & 24.9 & 3.7 & 10.7 & 11.1 & 30.8 \\
\hline $54.00+$ & 14.8 & 24.0 & 2.9 & 9.5 & 13.7 & 36.1 \\
\hline Poor & 12.9 & 36.2 & 3.7 & 11.0 & 6.7 & 29.7 \\
\hline Not poor & 15.5 & 27.3 & 2.6 & 9.3 & 11.7 & 31.1 \\
\hline
\end{tabular}

Source: Tabulations from the 1999 SIPP.

Note: Figures are weighted by the child's sample weight. 
and Sonenstein 2000). The distribution varies considerably by family characteristics. Relative care is much more frequent in black and Hispanic families than in white families, with center care less common for Hispanics, and father, nonrelative, and family day care less common for blacks. Families with a married mother are much more likely to use care by the father than are families with an unmarried mother, whereas the latter are more likely to use relative care. Center care is substituted for relative care, family day care, and other nonrelative care as children age. Father, mother, and relative care together account for 44 percent of arrangements for mothers who work full time, 60 percent for mothers who work part time, 42 percent of arrangements for mothers who work a day shift, and 66 percent for mothers who work nonday shifts. It is often asserted that there is a shortage of center care during evening and weekend work hours, but it is not clear whether the heavier use of informal arrangements during nonday shift hours reflects a shortage of more formal arrangements or greater availability of another family member to provide care. The distribution of types of care arrangements varies considerably by family income and poverty status. Loosely speaking, center and family day care and babysitters appear to be normal goods, substituted for relative care as income rises. However, this pattern may also be the result of a substitution effect: The opportunity cost of informal care is high in upper-income housholds if all potential earners in such households have relatively high wage rates.

One reason the distribution of child care by type is important is that it is closely associated with whether a family pays for child care. Unpaid child care arrangements are quite common and play an important role in the economic analysis of child care subsidies discussed in the next section. Table 7.6 describes the distribution of child care arrangements by payment status and the amount paid. Panel A shows that of families with an employed mother and at least one child under fifteen, the percentage who made any payment for child care fluctuated between 31 and 44 percent from 1985 to 1999 with an upward trend since 1991. Total weekly payments conditional on any payment showed a slight upward trend in real terms (1999 dollars) during the second half of the 1980s, from $\$ 91$ in 1985 to $\$ 97$ in 1988. Expenditure appears to have declined on average since 1988 to a low of $\$ 76$ in 1999 . However, changes in survey design during the 1990s may have affected the comparability of the figures. The percent of family income spent on child care increased slowly and steadily from 6.3 percent in 1986 to 7.5 percent in 1999. Panel B shows that in 199956 percent of families with a child under age six and an employed mother paid for child care. The incidence of payment and the amount paid tend to increase with family income, while the amount paid as a percentage of family income falls with the level of family income. Mothers working full time are much more likely to use paid care than mothers working part time, but conditional on paying for care the amount paid is 


\begin{tabular}{|c|c|c|c|}
\hline & $\%$ Paying & $\begin{array}{c}\text { Weekly Expense, } \\
\text { All Children } \\
\text { (if pay; \$1999) }\end{array}$ & $\begin{array}{l}\% \text { of } \\
\text { Income }\end{array}$ \\
\hline \multicolumn{4}{|c|}{ A. Families with Employed Mother, Children $<15$} \\
\hline Spring 1999 & 43.0 & 75.6 & 7.5 \\
\hline Spring 1997 & 44.1 & 74.7 & 7.4 \\
\hline Fall 1995 & 40.5 & 92.9 & 7.4 \\
\hline Fall 1993 & 35.5 & 85.1 & 7.3 \\
\hline Fall 1991 & 34.5 & 86.4 & 7.1 \\
\hline Fall 1990 & 38.0 & 87.6 & 6.9 \\
\hline Fall 1988 & 39.9 & 97.2 & 6.8 \\
\hline Fall 1987 & 33.3 & 94.7 & 6.6 \\
\hline Fall 1986 & 31.4 & 93.6 & 6.3 \\
\hline Winter 1985 & 33.7 & 90.6 & n.a. \\
\hline \multicolumn{4}{|c|}{ B. Spring 1999, Families with Employed Mother, Child $<6$ Only } \\
\hline All & 56.1 & 88.9 & 9.0 \\
\hline \multicolumn{4}{|c|}{$\begin{array}{l}\text { Annual family income } \\
\qquad(\$ 000)\end{array}$} \\
\hline$<18.00$ & 51.0 & 57.9 & 22.2 \\
\hline $18.00-35.99$ & 47.9 & 80.6 & 11.9 \\
\hline $36.00-53.99$ & 57.4 & 81.4 & 7.2 \\
\hline $54.00+$ & 62.2 & 105.8 & 5.0 \\
\hline Below poverty line & 44.0 & 67.7 & 33.1 \\
\hline Above poverty line & 57.3 & 90.5 & 7.5 \\
\hline Full-time employee & 63.9 & 92.7 & 8.6 \\
\hline Part-time employee & 41.1 & 77.0 & 5.7 \\
\hline Married & 58.0 & 95.2 & 6.8 \\
\hline \multicolumn{4}{|c|}{ Widowed, divorced, or } \\
\hline separated & 62.0 & 77.0 & 14.0 \\
\hline Never married & 48.4 & 69.3 & 12.5 \\
\hline
\end{tabular}

Source: Tabulations from the 1997 and 1999 SIPP, and Smith (2002).

Note: N.a. indicates data not available.

only $\$ 15$ higher for full-time than for part-time care. Married and previously married mothers are more likely to pay than never-married mothers. ${ }^{11}$

\subsection{Economic Issues}

This section discusses three important economic issues concerning child care subsidies for low-income families: First, why does the government

11. See Giannarelli and Barsimontov (2000) for comparable data from the 1997 National Survey of America's Families. Data from the 1990 NCCS show that paying for care is much less common when the mother is not employed and when the youngest child is school age (Hofferth et al. 1991). Relative care is least likely to be paid, with the largest percentage of relatives paid being 36 percent for employed mothers of children under five. For employed mothers, centers, babysitters, and family day care arrangements are almost always paid, but for nonemployed mothers unpaid arrangements of these types are quite common. 
subsidize child care? Is there a market failure? If so, what is the source of market failure, and under what conditions can subsidies help to correct the failure and improve resource allocation? Or are child care subsidies merely a form of income redistribution? Second, what are the work incentives caused by child care subsidy programs? How does the availability of informal (unpaid) child care affect these incentives? How effective are child care subsidies compared to employment subsidies in achieving the goal of economic self-sufficiency? To what extent do child care subsidies crowd out private child care expenditures by mothers who would have worked anyway? Third, what are the effects of child care subsidies on the quality of child care and on child well-being? How are these effects influenced by the form of the subsidy? How do subsidies of different types affect incentives for parents to purchase high-quality care?

\subsubsection{Why Subsidize Child Care?}

Three main arguments have been used in support of government subsidies to child care. The arguments are based on attaining economic selfsufficiency, child care market imperfections, and distributional considerations.

\section{Self-Sufficiency}

Child care subsidies can help low-income families be economically selfsufficient. Self-sufficient in this context means employed and not enrolled in cash-assistance welfare programs. Self-sufficiency may be a desirable goal for noneconomic reasons, but it also may be considered desirable if it increases future self-sufficiency by inculcating a work ethic and generating human capital, thereby saving the government money in the long run (Robins 1991, 15). These arguments explain why many child care subsidies are conditioned on employment or other work-related activities such as education and training. Child care and other subsidies paid to employed lowincome parents may cost the government more today than would cash assistance through TANF. But if the dynamic links suggested above are important, then these employment-related subsidies could result in increased future wages and hours worked and lower lifetime subsidies than the alternative of cash assistance both today and in the future. Note that this argument has nothing to do with the effects of child care on children, and there are few restrictions on the type and quality of child care that can be purchased with employment-related subsidies such as the CCDF and DCTC. There is little evidence either for or against the existence of strong enough dynamic links to make means-tested employment-conditioned child care subsidies cost-effective for the government in the long run. ${ }^{12}$

12. There is substantial evidence of positive serial correlation in employment. Whether this is due to "state dependence" (working today changes preferences or constraints in such a way 
Walker (1996) has argued that difficulties in attaining economic selfsufficiency are caused by imperfections in the credit market, not the child care market. If the dynamic links suggested above are important, then a family could borrow against its future earnings in a perfect credit market to finance the child care needed in order to be employed today and gain the higher future earnings that result from employment today. Imperfection in the credit market caused by moral hazard and adverse selection prevent this, but the remedy according to Walker lies in government intervention in the credit market, not the child care market. Walker's proposal is discussed in section 7.6.

\section{Market Imperfections}

The second main argument in favor of government child care subsidies is imperfection in the child care market. The imperfections that are often cited as a basis for government intervention are imperfect information available to parents about the quality of care, and positive external benefits to society generated by high-quality child care. ${ }^{13}$ These considerations can be used to argue for child care subsidies to all families, since the externalities and information problems are not necessarily income-specific. ${ }^{14}$ Walker (1991) spells out these points in detail; the discussion here follows his arguments closely. ${ }^{15}$ There is imperfect information in the child care market because consumers are not perfectly informed about the identity of all potential suppliers, and because the quality of care offered by any particular supplier identified by a consumer is not fully known. A potential remedy for the first problem is government subsidies to resource and referral $(R \& R)$ agencies to maintain comprehensive and accurate lists of suppliers. This may not solve the problem in practice because of very high turnover and unwillingness to reveal their identity among informal child care providers. The second information problem is that consumers know less about product quality than does the provider, and monitoring is costly. This can lead to moral hazard

as to make working in the future more attractive) or unobserved heterogeneity (working today does not affect the attractiveness of future work; some people find work more attractive than others in every period) is unclear. See Heckman (1981) for an early discussion and Hyslop (1999) for recent evidence. I am not aware of any evidence on this issue that is specific to the low-income population. Gladden and Taber (2000) analyze the effect of work experience on wage growth for less-skilled workers.

13. It is often claimed that there are shortages of child care of particular types such as center care for infants, night shift care, and care for sick children. Most of these claims are by non-economists who use the term "shortage" in the usual noneconomic sense that providers are not willing to supply much child care of these types at prices that most consumers are willing to pay. See Waller (1997) for an example.

14. Evidence summarized by Currie (2001) suggests that the benefits of high-quality preschool programs are larger for the most disadvantaged children than for other children. If the magnitude of the externalities and/or information problems that are the source of market imperfections are proportional to the gains from high-quality care, then this would suggest that subsidies be targeted to disadvantaged children.

15. See also Council of Economic Advisors (1997), Magenheim (1995), Robins (1991), and U.S. Department of Health and Human Services (2001). 
and/or adverse selection. Moral hazard is a plausible outcome in day care centers (e.g., changing diapers only before pick-up time). Adverse selection of providers is plausible in the more informal family day care sector: Family day care is a very low-wage occupation, so women with high wage offers in other occupations are less likely to choose to be care providers. If the outside wage offer is positively correlated with the quality of care provided, then adverse selection would result. Regulations are often suggested as a solution to this information problem, but Walker notes that the monitoring required to enforce regulations may be costlier for the government than for consumers. He also points out that the conditions under which regulations are beneficial to consumers are unlikely to be satisfied in the child care market. ${ }^{16}$

Some evidence suggests that parents do not obtain much information about the child care market before making a choice. Walker (1991) reports that 60-80 percent of child care arrangements made by low-income parents are located through referrals from friends and relatives or from direct acquaintance with the provider. This suggests that consumers may not be well-informed about potential providers, but it does not prove that a suboptimal amount of information is used by consumers. If consumers have strong preferences for acquaintance with the provider, then limited information may be optimal from the parents' perspective, although not necessarily from a social perspective if acquaintance is uncorrelated with quality of care. A referral from friends and relatives or direct acquaintance with the provider may serve as a signal of quality to parents, but it may not be a good signal of the developmental appropriateness of child care if parents are not good judges of the quality of child care. Cryer and Burchinal (1995) report a direct comparison of parent ratings of various aspects of the developmental appropriateness of their child's day care center classroom with trained observer ratings of the same aspects, using data from the Cost, Quality, and Outcomes study. The results show that parents give higher average ratings on every item than do trained observers, by about 1 standard deviation on average for preschool age classrooms and by about 2 standard deviations on average for infant and toddler rooms. The instrument containing these items is of demonstrated reliability when administered by trained observers, so this suggests that parents are not well-informed about the quality of care in the arrangements used by their children. ${ }^{17}$ Child care

16. See Walker (1991, 68-69), which is based on applying Leland's (1979) model of regulations to the child care market. The conditions are low price elasticity of demand, relevance of quality to consumers, low marginal cost of quality, and consumers' placing a low value on low-quality care.

17. The instrument is the Early Childhood Environment Rating Scale (ECERS) and its counterpart for infants and toddlers, the Infant-Toddler Environment Rating Scale (ITERS). See Harms and Clifford (1980) and Harms, Cryer, and Clifford (1990) for discussion of the instruments. Helburn (1995) discusses their reliability in the Cost, Quality, and Outcomes study. The correlation between parent and observer scores was .21 for infant-toddler rooms and .29 for preschool rooms (Cryer and Burchinal 1995, 206). Thus parents do appear to have some ability to distinguish among programs of different quality. However, from a child development perspective it is the absolute level of quality that matters, not relative quality. 
subsidies targeted at high-quality providers could induce parents to use higher quality care by reducing the relative price of such care. This would not necessarily remedy the information problem, but it would deal with a consequence of that problem, namely a level of child care quality that is suboptimal from the perspective of society.

The externality argument is a standard one and closely parallels the reasoning applied to education. High-quality child care may lead to improved intellectual and social development, which in turn increases schoolreadiness and completion and thereby reduces the cost to society of problems associated with low education: crime, drug use, teenage childbearing, and so forth. If parents do not account for the external benefits of highquality child care, then they use child care of less than optimal quality. This argument could rationalize subsidies targeted to high-quality providers, such as Head Start. The evidence that child care quality affects child development is of two main types. The first is from randomized assignment studies that have evaluated the impact of high-quality preschool programs for disadvantaged children. A comprehensive review of early childhood interventions by Karoly et al. (1998; discussed in more detail in section 7.5) concludes that such programs can provide significant benefits to participating children and can reduce future expenditures on welfare, criminal justice, and related items. The second type of evidence is from observational studies of children placed by their parents in child care arrangements of varying quality. Such studies have generally not followed the children long enough to determine whether any observed developmental gains are long lasting and whether there are subsequent effects on school outcomes. Also, there have been few efforts to determine whether results are robust to controls for self-selection and unobserved heterogeneity. Love, Schochet, and Meckstroth (1996) review this literature and conclude that higher child care quality is associated with better social skills, cooperation, and language development, and fewer behavior problems. But they acknowledge the limitations of existing evidence. The evidence cited by Karoly et al. is compelling but is based mainly on very intensive and costly programs that are quite different even from Head Start. It is unclear whether child care of moderately high quality provides positive but proportionately smaller developmental benefits, or whether there exists a threshold of quality below which benefits are negligible.

\section{Distributional Issues}

The third argument for government child care subsidies is based on distributional considerations related both to cross-sectional equity at a given time and to the long-run benefits to children of high-quality child care. For example, Bergmann (1996) argues that high-quality child care can be thought of as a "merit good, something that in our ethical judgment everybody should have, whether or not they are willing or able to buy it" (p. 131). 
This would justify in-kind subsidies aimed at low-income families, but also at middle- and upper-income families if positive social externalities of high-quality child care are prevalent throughout the income distribution. In its pure form this argument is based solely on the moral grounds that it is unethical to deprive any child of the optimum conditions for development if society has the resources to provide such conditions.

Bergmann argues that the usual economic considerations in favor of cash transfers over in-kind subsidies do not apply to merit goods. The main arguments she advances are that children have little or no say in how parents spend a cash grant; that society has a responsibility to ensure that children are well cared for while the parents work; and that high-quality child care has benefits to children that parents may not fully account for in their spending decisions. These arguments suggest an in-kind subsidy program for child care that is restricted to high-quality care, an issue discussed in depth below. There has apparently been no research on the implicit cash value of in-kind child care subsidies, or on the rate at which child care subsidies "crowd out" private child care expenditures. ${ }^{18}$

\subsubsection{Work Incentives in Child Care Subsidy Programs}

Child care subsidies generally increase a parent's incentive to be employed. ${ }^{19}$ Most child care expenditures are made in order that a parent may work. A child care subsidy reduces this work-related expense and therefore increases the net return from employment. However, many parents have access to child care by relatives at no monetary cost. Subsidies will influence the trade-off between paid and unpaid child care, and this may affect the magnitude of the work incentive of a child care subsidy. Subsidies targeted at low-income families are usually phased out as income rises, and this will influence the work incentive of the subsidies. This subsection begins with a simple model that ignores these complications as well as issues involving the quality of care. This provides a baseline for subsequent consideration of the issues raised by unpaid care, phaseout, and the quality of child care.

\section{A Simple Model}

The canonical static one-person labor supply model (Pencavel 1986) augmented with assumptions about child care is a useful vehicle for analysis of work incentive effects of child care subsidies. The mother is assumed to be the caretaker of her children, so she is the agent in the model. Suppose that child care is homogeneous in quality and commands a mar-

18. Besharov and Samari (2000) discuss vouchers versus cash payments for child care subsidies. They note that some states are switching CCDF subsidies from vouchers to cash.

19. If a mother works only in order to afford to purchase high-quality child care, then a child care subsidy could reduce her incentive to work. See Gelbach (2002) for a discussion of this and related possibilities. 


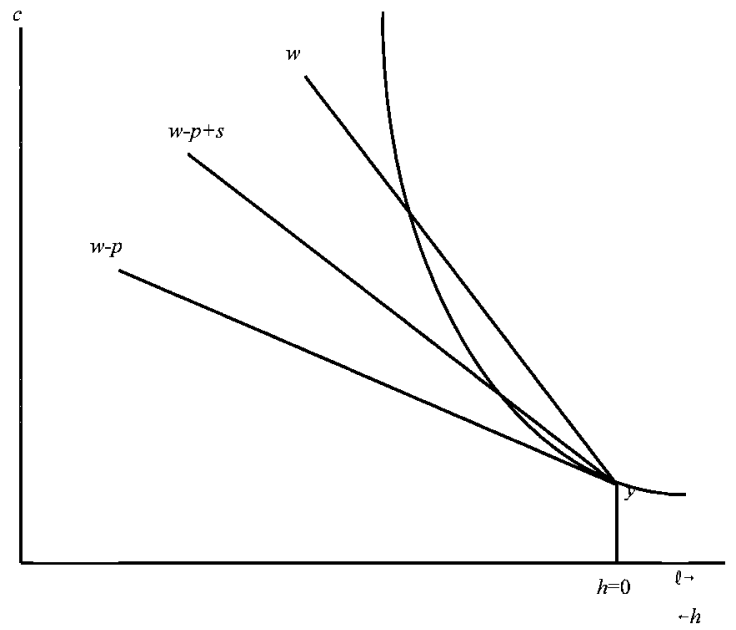

Fig. 7.1 Child care price and a linear subsidy

ket price of $p$ dollars per hour of care per child, taken as given by the mother. ${ }^{20}$ There is no informal unpaid care available and the mother cannot care for her children while she works, so paid child care is required for every hour the mother works. By assumption, the mother cares for her children during all hours in which she is not working. There are no fixed costs of work, and the wage rate $w$ is the same for each hour of work. For simplicity, suppose there is only one child who needs care. The mother's budget constraint is $c=I=y+(w-p) h$, where $c$ is consumption expenditure other than child care, $I$ is income net of child care expenditure, $y$ is nonwage income, and $h$ is hours of work. The time constraint is $h+\ell=1$, where $\ell$ is hours of leisure, and the utility function is $u(c, \ell)$ The monetary cost of child care reduces the net wage rate $(w-p)$, making the slope of the budget line in consumption-leisure space flatter than if child care was free, as illustrated in figure 7.1. A higher price of child care increases the likelihood that the net market wage is below the reservation wage (the slope of the indifference curve at $h=0$ ), thereby reducing the likelihood of employment.

A linear child care subsidy of $s$ dollars per hour changes the budget constraint to $c=y+(w-p+s) h$, raises the net wage, makes the budget line

20. Homogeneous quality means that we can ignore for now the possibility that the mother cares about child outcomes. Child outcomes in this model can be influenced by only two things: the quality of purchased care, which is fixed by assumption for now, and the quality of the mother's care, which in this very simple model we can think of as being a component of the marginal utility of leisure. This assumption will be relaxed below. A mother who perceives that she is a low-quality caregiver can be interpreted in this simple model as having a low marginal utility of leisure. She will be more likely to work, other things equal, in order to take advantage of the higher quality substitute care available in the market. 


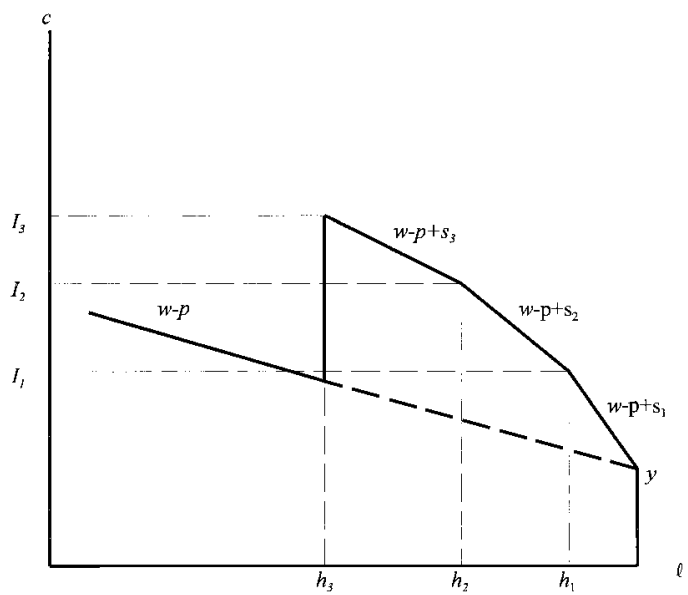

Fig. 7.2 A nonlinear child care subsidy

steeper, and thereby increases the likelihood of work. For the preferences and constraints shown in figure 7.1, the mother would not work in the absence of the subsidy, and the subsidy is large enough to induce her to work. The effect of such a subsidy on hours of work conditional on employment is indeterminate because the subsidy has a positive substitution effect and a negative income effect on hours of work. In this simple model, a wage subsidy such as provided by the EITC (which is linear in the phase-in region of the credit) is equivalent to a child care subsidy of the same amount and has the same incentives.

\section{Nonlinear Subsidy}

Most child care subsidies do not have the simple linear form described above. As shown in table 7.3, states typically structure their CCDF subsidies to have a declining subsidy rate as income rises, and a maximum income level for eligibility. ${ }^{21}$ A generic example of such a structure is illustrated in figure 7.2. The subsidy rate declines from $s_{1}$ to $s_{2}$ at income level $I_{1}$, corresponding to hours of work $h_{1}$, and from $s_{2}$ to $s_{3}$ at income level $I_{2}$, corresponding to hours $h_{2}$. The subsidy rate remains constant at $s_{3}$ until the income eligibility cutoff $I_{3}$, corresponding to hours $h_{3}$, is reached, and then drops to zero, resulting in a "notch" or "cliff" in the budget constraint. A nonlinear subsidy of this type does not alter the qualitative result that a child care subsidy creates a work incentive. It does affect the incentive to locate at any particular positive level of $h$, compared to a linear subsidy, 
and could induce some mothers to reduce hours from above $h_{3}$ to $h_{3}$ or less in order to qualify for a subsidy. ${ }^{22}$

\section{Unpaid Child Care}

Some families have access to care by a relative, including the father or another family member, at no monetary cost. But not all families with access to such care use it, because it has an opportunity cost: The father or other relative sacrifices leisure or earnings in order to provide care. The quality of such care compared to the quality of market care is also likely to influence the use of informal care, but consideration of quality is taken up below and ignored here. If the mother pools income with the father or relative or has preferences over the father or relative's leisure hours, then the mother will behave as if unpaid child care has an opportunity cost. To illustrate in the simplest possible setting, take as given that the relative who is the potential unpaid child care provider is not employed. ${ }^{23}$ Let $H$ represent hours of paid child care purchased in the market and $U$ hours of unpaid child care provided by the relative. ${ }^{24}$ Maintaining the assumption that the mother is the caregiver during all hours in which she is not employed, we have $h=H+U$, and $h \geq H, U \geq 0$. The budget constraint is $c=y+$ $w h-p H$. The utility function is $\mathrm{u}\left(\mathrm{c}, \ell, \ell_{r}\right)$, where $\ell_{r}$ is leisure hours of the relative. The time constraints are $\ell+h=1$ for the mother, and $\ell_{r}+U=1$ for the relative. If $U$ and $H$ are both positive, then the shadow price of an hour of relative care is the marginal utility of the relative's leisure. In this case relative care is used for the number of hours $U^{*}$ for which the marginal rate of substitution between consumption and leisure of the relative equals the market price of care: $u_{\ell r} / u_{c}=p$; and paid care is used for the remaining $H^{*}=h-U^{*}$ hours for which child care is required.

In order to examine the work incentive effects of a child care subsidy in this model, classify outcomes as follows:

\begin{tabular}{lccc}
\hline Outcome & Mother Employed & Unpaid Care Used & Paid Care used \\
\hline 1 & no & no & no \\
2 & yes & yes & no \\
3 & yes & yes & yes \\
4 & yes & no & yes \\
\hline
\end{tabular}

22. Another form of nonlinear subsidy is a subsidy for a fixed dollar amount or a fixed amount of care independent of the mother's hours of work and employment status. Head Start is an example of such a subsidy: Care is free for half the day. Public schools provide another example (Gelbach 2002). This type of subsidy is discussed below.

23. See Blau and Robins (1988) for a model in which the relative's employment status is a choice variable. This extension does not change the qualitative implications of the analysis.

24. The key distinction is paid versus unpaid, not relative versus nonrelative. Some relatives are in fact paid for child care. Paid care by a relative would be classified here as part of $H$, not $U$. Subsidies such as the DCTC and CCDF that allow paid care by a relative require that the relative not be coresident with the mother. 
A linear child care subsidy reduces the effective price of market care from $p$ to $p-s$ but does not affect the price of unpaid relative care, because no money changes hands for such care. A subsidy therefore increases the probability of choosing outcomes 3 and 4 and reduces the probability of choosing outcomes 1 and 2. Notice that in addition to providing a work incentive for the mother (outcome 1 is less likely) a subsidy also provides an incentive to use paid care conditional on the mother working (outcome 2 is less likely). So in the presence of an unpaid care option, a subsidy will induce some women who would have worked anyway to increase use of paid care and reduce use of unpaid care in order to qualify for the subsidy. Thus a subsidy to paid child care "crowds out" unpaid care. ${ }^{25} \mathrm{~A}$ child care subsidy will have income effects on all goods, so the additional expenditure on child care by families who would have paid for care in the absence of a subsidy will be less than the amount of the subsidy. Private child care expenditures are crowded out.

Is a child care subsidy the most cost-effective way for the government to increase employment of low-income mothers of young children? An obvious alternative is a wage subsidy such as the Earned Income Tax Credit (EITC). Child care subsidies are available only if paid care is used, and some mothers will prefer to use unpaid care and pass up the subsidy. This could make a child care subsidy more effective at increasing employment per subsidy dollar spent than a wage subsidy. On the other hand, a child care subsidy will induce some mothers who would have worked anyway to switch from unpaid to paid care, causing an increase in government expenditure with no resulting increase in employment. Some insight can be gained by making a few simplifying assumptions. Suppose that hours worked per worker are not affected by wage or child care subsidies (income and substitution effects exactly offset); the wage and child care price are not affected by subsidies (no general equilibrium effects); all mothers who are induced to work by the subsidy use paid care; and both subsidies are additive (for analytic convenience). Under these assumptions, the number of additional hours of work per dollar spent by the government on a wage subsidy of $e$ dollars per hour of work is $\eta_{N w} /\left(w+e \eta_{N w}\right)$, where $\eta_{N w}$ is the elasticity of employment $(N)$ with respect to the wage rate. The additional hours of work per dollar spent by the government on a child care subsidy of $s$ dollars per hour of paid care is $-\eta_{N_{p}} /\left(p \theta-\eta_{N_{p}} s-\theta s \eta_{P p}\right)$, where $\eta_{N_{p}}$ is the elasticity of employment with respect to the price of paid care, $\theta$ is the proportion of working mothers who use paid care, and $\eta_{P p}$ is the elasticity of paid care use with respect to the price of care conditional on employment. For a wide range of plausible values of the parameters and variables,

25. A subsidy could induce a mother to pay for care by a relative that would have been unpaid in the absence of a subsidy. Allowing for this possibility would complicate the model but would not alter any of the results discussed here. 
an additive child care subsidy that is a given proportion of the child care price generates many more additional hours worked per dollar of government expenditure than an additive wage subsidy of the same proportion of the wage. ${ }^{26}$ This may seem surprising, because a wage subsidy appears to be a more direct instrument for increasing employment. But a wage subsidy provides benefits to all working mothers, including those who use unpaid child care, whereas a child care subsidy provides no benefit to the latter group. It is the reluctance of some mothers to use paid care that makes a child care subsidy a more cost-effective method of increasing employment. If all working mothers used paid care then there would be no difference in the cost effectiveness of the two subsidies if they were set at the same proportional level (see the appendix).

\subsubsection{Quality of Child Care}

If the quality of market child care is variable and if the quality of care affects child outcomes, then the mother will be concerned about the quality of care she purchases. The simplest case to consider is unidimensional quality: Quality is a single "thing." The price of an hour of child care is $p=$ $\alpha+\beta q$, where $q$ is the quality of care and $\alpha$ and $\beta$ are parameters determined in the market. Think of this as a hedonic price function determined by the market supply of and demand for quality (a linear price function is not essential to the argument). The mother cares about the quality of child care because it affects her child's development outcome, $d$. Let the child development production function be $d=d\left(\ell q_{m}, h q\right)$, where $q_{m}$ is the quality of the care provided by the mother. The effect of purchased child care on development depends on its quantity $(h)$ and quality $(q)$. For simplicity, no distinction is made between the mother's leisure and her time input to child development, and assume also for simplicity that no unpaid care is available. Relaxing these assumptions does not change the main implications of the model. Assume for the moment that child care subsidies are available only if the mother is employed. The utility function is $\mathrm{u}(c, \ell, d)$ and the budget constraint is $c=y+[w-(\alpha+\beta q)] h$.

Most existing child care subsidies can be interpreted as affecting $\alpha$ but $\operatorname{not} \beta$, because they are independent of the quality of care. Some subsidies, such as the DCTC, are explicitly independent of quality. Others, such as the CCDF, can be used only in arrangements that satisfy state licensing standards or are legally exempt from such standards. Such subsidies can be thought of as being subject to a quality threshold but independent of quality beyond the threshold. Thus they do not alter the effective marginal price of quality, $\beta h$, faced by the consumer (ignoring equilibrium effects). The two issues considered here are how child care subsidies affect the incentive to work and how they affect the demand for quality. A subsidy that reduces

26. See the appendix for the derivation of the formulas and illustrative calculations. 
$\alpha$ or $\beta$ increases the incentive to be employed because it reduces the monetary cost of child care when employed, and it has no impact on utility when not employed. One might expect that such a subsidy would also cause an increase in the level of quality demanded conditional on being employed, which raises the net price of an hour of child care. However, in a quality-quantity model the interaction between quality and quantity yields substitution effects of market prices that cannot be signed (Becker and Lewis 1973).

Nevertheless, the following two results from this model can be demonstrated (see the appendix for proofs). A subsidy that is independent of quality - call it an $\alpha$-subsidy - has a bigger positive effect on employment than a subsidy that is quality-specific, a $\beta$-subsidy. So if the goal of a subsidy program is to facilitate employment, this is best accomplished by an $\alpha$-subsidy. The second result is for the relative magnitude of the effect of $\alpha$ subsidies and $\beta$-subsidies on the demand for quality. In a quality-quantity model the substitution effect of a change in price on the level of quality demanded is ambiguous, and this holds for changes in both $\alpha$ and $\beta$. But it can be shown that (a) if the substitution effects $\partial q /\left.\partial \alpha\right|_{\bar{u}}$ and $\partial q /\left.\partial \beta\right|_{\bar{u}}$ are both negative, then $\partial q /\left.\partial \beta\right|_{\bar{u}}$ is larger in absolute value than $\partial q /\left.\partial \alpha\right|_{\bar{u}}$; and (b) if $\partial q /$ $\left.\partial \alpha\right|_{\bar{u}}>0$ then either $\partial q /\left.\partial \beta\right|_{\bar{u}}$ is positive but smaller than $\partial q /\left.\partial \alpha\right|_{\bar{u}}$ or $\partial q /\left.\partial \beta\right|_{\bar{u}}$ $<0$. Thus a $\beta$-subsidy has a bigger positive effect or a smaller negative effect on the level of quality demanded than an $\alpha$-subsidy. So if the goal of a subsidy program is to improve the level of quality of child care to which children are exposed, this is best accomplished by a $\beta$-subsidy. These results illustrate the policy trade-off described earlier: Policies that are most effective at accomplishing one goal will not be as useful in accomplishing the other goal of policy. The model is very simple, but this trade-off will hold in more general models as well.

Now consider the case in which paid child care can be used to enhance child development even when the mother is not employed. This allows us to consider the effects of a subsidy like the Head Start program on work and child care quality incentives. Maintain the assumption that no unpaid child care is available. Head Start provides $h^{*}$ hours of child care of quality $q^{*}$ at no monetary cost, where $h^{*}$ and $q^{*}$ are taken as given by the mother. If she works fewer than $h^{*}$ hours then she does not incur any monetary child care cost. If she works more than $h^{*}$ hours and less than $h^{\prime}$ hours, where $h^{\prime}$ is the number of hours at which her income exceeds the eligibility threshold for Head Start, then she incurs costs of $p\left(h-h^{*}\right)$ for child care, where as before $p=\alpha+\beta q$ and $q$ is the quality of care purchased. For $h>h^{\prime}$ she receives no subsidy. For a low-wage mother, it is reasonable to assume that $h^{*}<h^{\prime}$. Assume for simplicity that child care in excess of the $h^{*}$ hours provided by Head Start is used only for employment purposes, not for child development. Also assume that the Head Start subsidy is taken up if offered. 


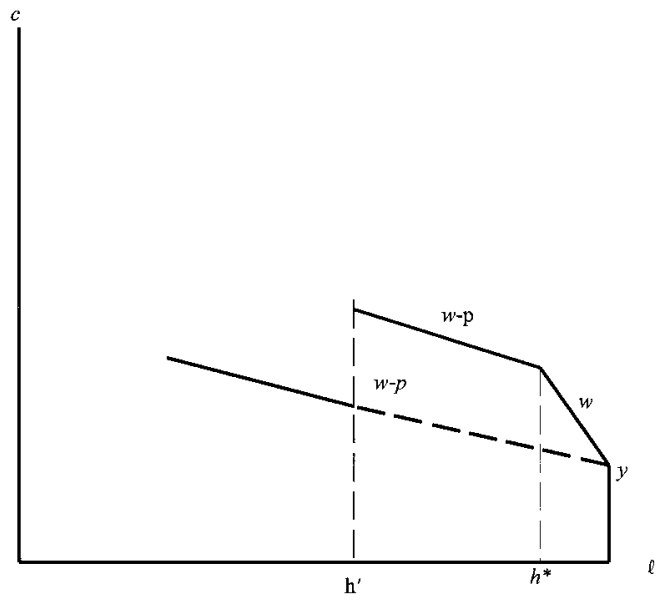

Fig. 7.3 Head Start

Ignoring quality for the moment, the budget constraint under Head Start is depicted in figure 7.3, with the subsidy rate along the first segment $s_{1}=p$, the subsidy rate along the second and third segments zero, a kink at $h^{*}$, and a notch at $h^{\prime}$. The subsidy clearly provides a work incentive for mothers who would not have worked in the absence of the subsidy, with $h$ $=h^{*}$ a likely outcome given the kink in the budget constraint at $h^{*}$. The subsidy has offsetting substitution and income effects for mothers who would have worked $h^{*} \geq h>0$ hours in the absence of the subsidy. The subsidy causes only an income effect for mothers who would have worked $h^{\prime}>$ $h>h^{*}$ hours in the absence of the subsidy, and it therefore causes a reduction in their hours worked. ${ }^{27}$ The subsidy has a work disincentive effect for mothers who would have worked more than $h^{\prime}$ hours in the absence of the subsidy. A marginal change in the subsidy (i.e., a change in $h^{*}$ ) has no effect on work incentives for mothers who are not induced to work by the subsidy. Such mothers do not work because their wage rate is too low compared to their reservation wage even in the absence of monetary child care costs, so offering them additional hours of free child care does not change their incentives.

The effect of a Head Start subsidy on child development is uncertain because it depends on the quality of child care that would have been purchased in the absence of the subsidy, and on the quality of additional child care purchased beyond the subsidized hours of care. It seems likely that $q^{*}$ is relatively high and that the average quality of care experienced by a child as a result of the Head Start subsidy will increase. If it is assumed that $q^{*}$ is greater than or equal to the highest quality care available in the market,

27. Gelbach (2002) presents a similar analysis of the work incentives of free public school. 
then the Head Start subsidy results in an improvement in child development. Marginal changes in $h^{*}$ and $q^{*}$ have ambiguous effects on the level of quality demanded by mothers who purchase additional hours of care beyond the $h^{*}$ free hours provided by the subsidy. A comparison of the effects on quality of Head Start and price subsidies ( $\alpha$ and $\beta$-subsidies) also yields ambiguous results.

\subsection{Evidence}

This section describes evidence on the employment and child care quality effects of means-tested child care subsidies. The evidence discussed is from three types of studies: evaluations of experimental demonstration projects, evaluations of actual child care subsidy programs, and studies of the effects of the price of child care. The latter type of study does not directly measure subsidies and their impact but infers the impact of subsidies from the estimated price effects. This type of study is the least direct but by far the most common. The first three subsections focus on evidence pertaining to employment, and the fourth subsection discusses the much more limited evidence available on child care quality and other outcomes.

\subsubsection{Demonstrations}

Several demonstration programs designed to help low-income families achieve economic independence included child care subsidies along with other benefits and services. These programs were evaluated using randomized assignment methods, so the average effects of the programs on outcomes of interest are estimated without bias by simple comparisons of treatment and control group averages. However, in each case the child care subsidy was only one of several services provided as part of the program, so it is not possible to determine how much of the program impacts were due to the child care subsidy..$^{28}$ I discuss one example of a demonstration program in order to illustrate the nature of the evidence from such programs.

New Hope was a program intended to reduce poverty among the lowincome population in Milwaukee (Bos et al. 1999). It operated from 1994 through 1998 with broad eligibility rules that made virtually anyone with low income eligible to enroll, regardless of employment and family status. The program was voluntary and provided an earnings supplement, afford-

28. A 1989 randomized experiment in Mecklenberg County, North Carolina offered a treatment group of 300 AFDC mothers guaranteed access to subsidized child care for up to one year within two weeks of taking a full-time job, while a control group of 302 AFDC mothers had access to subsidized child care only through a long waiting list with an average wait of six to ten months. However, the offer was made by mail with no telephone or personal contacts, and the take-up rate was very low: Only one-sixth of the treatment group applied for and received a subsidy. The treatment had no significant impact on welfare participation or expenditure. See Bowen and Neenan (1993) for details. 
able health insurance, a child care subsidy, and a full-time community service job if no other employment was available. The program required fulltime employment (thirty hours per week) and provided benefits for up to three years. Participants made their own child care arrangements and were reimbursed for most of the expenses, with a copayment that increased with family income. Thirty-nine percent of participants with children used child care at an average subsidy of $\$ 2,376$ over two years. An early evaluation based on two years of data from the program found that among individuals who were not employed at entry to the program, participation in the program increased employment by 7 percentage points, boosted earnings by about $\$ 700$ per year (13 percent), raised income by 12 percent, and had no impact on welfare participation. The program had no statistically significant effects on employment and earnings for those who were employed for at least thirty hours per week at entry, although the sample size was small (the point estimate of the earnings impact was $-\$ 571$ per year), and reduced AFDC and food stamp participation by 7-10 percent in year two. The program increased use of formal child care by 7.4 percent for boys and 12.5 percent for girls, and it resulted in improved academic performance, study skills, social competence, and behavior among boys but not girls. ${ }^{29}$

\subsubsection{Actual Subsidy Programs}

Four studies have estimated the impact of actual child care subsidies on employment. Two evaluate means-tested state subsidies for low-income families funded by federal programs prior to the 1996 welfare reform. A third study evaluates the labor supply effects of the implicit child care subsidy provided by free public school. This is not a means-tested subsidy (and is not usually thought of as a child care subsidy at all), but information about its impact could be useful for evaluating the effects of means-tested child care subsidies with a similar structure. The fourth evaluates the impact of subsidies in a sample of thirteen states in 1997. In each of these studies the subsidy recipients are self-selected, and the studies recognize and attempt to deal with the possibility of selectivity bias.

29. Other demonstrations and experiments that included child care subsidies were the Teenage Parent Demonstration (Kisker, Rangarajan, and Boller 1998), New Chance (Quint, Bos, and Polit 1997), GAIN in California (Riccio, Friedlander, and Freedman 1994), the National Evaluation of Welfare-to-Work Strategies, formerly known as the JOBS program (Hamilton et al. 1997), the Minnesota Family Investment Program (Miller et al. 1997), the Florida Family Transition Program (Bloom et al. 1999), and the Gary, Seattle, and Denver Income Maintenance Experiments. The GAIN demonstration excluded children under age six. Granger and Cytron (1999) report that the effects of the Teenage Parent Demonstration and New Chance (which was also targeted at teenage mothers) on use of center-based child care were smaller than in New Hope and often statistically insignificant. Robins and Spiegelman (1978) estimate that eligibility for a SIME-DIME child care subsidy increased use of market child care by 18 percentage points in Seattle and 14 percentage points in Denver. Results for child care use in the other demonstrations are not available. See Hamilton, Freedman, and McGroder (2000) for a summary of the effects of all the recent demonstration programs. 
Berger and Black (1992; hereafter BB) evaluate the employment impact of two Kentucky child care subsidy programs funded by Title XX in 1989. Both programs subsidized slots in licensed day care centers only and imposed a work requirement of at least twenty hours per week. One program reimbursed day care centers directly for up to $\$ 40$ per week, depending on family income, and had an income eligibility limit of 60 percent of state median income; the corresponding figures for the other program were $\$ 50$ and 80 percent. The two programs are treated by BB as a single program. BB administered a telephone survey to single mothers who were either subsidy recipients or on the wait list for a subsidy. The employment status of subsidy recipients was ascertained for periods both before and after they entered the wait list. In addition, a sample of single mothers in Kentucky was drawn from the May 1988 Current Population Survey (CPS).

$\mathrm{BB}$ recognize that if program administrators select subsidy recipients on the basis of characteristics not observed by the investigators, then the wait list would not be a valid control group for the subsidy recipients. Furthermore, the wait list itself may be self-selected if women who are more motivated to work are more likely both to seek a subsidy and to be employed even in the absence of a subsidy. BB pool the before and after observations from subsidy recipients and the wait list with the CPS sample in a regression model with the following specification: EMP $=\alpha_{0}+\alpha_{1} \mathrm{WL}_{t-1}+$ $\alpha_{2} \mathrm{WL}_{t}+\alpha_{3} \mathrm{SUB}_{t-1}+\alpha_{4} \mathrm{SUB}_{t}+\beta \mathbf{X}+u$, where EMP is an indicator for being employed, WL is an indicator for the wait list group, SUB is an indicator for subsidy recipients, $t-1$ is the "before" observation (before beginning to receive a subsidy for the subsidy recipients, and before entering the wait list for the wait list group), $t$ is the "after" observation, the CPS sample is the reference group, $X$ is a vector of control variables, and $u$ is a disturbance. BB refer to $\alpha_{1}$ as the "sign-up effect" (self-selection into the wait list), $\alpha_{2}-\alpha_{1}$ as the "wait list effect" (the employment effect of entering the wait list), $\alpha_{3}-\alpha_{2}$ as the "creaming effect" (selection of recipients from the wait list by administrators on the basis of unobservables), and $\alpha_{4}-\alpha_{3}$ as the "subsidy effect" (the before-after difference in employment of eventual recipients).

The estimates show a sign-up effect of 22.6 percentage points, a wait list effect of 16.9 percentage points, a creaming effect of 4.0 percentage points, and a subsidy effect of 8.4 points, all significantly different from zero except the creaming effect. $\mathrm{BB}$ view the sign-up and creaming effects as selection effects that are not part of the true subsidy effect. However, they suggest that the wait list effect could be either a selection effect (i.e., the employment rate of the wait list group would have increased even if they had not applied to the program) or part of the impact of the subsidy as mothers go to work in anticipation of needing to meet the work requirement upon being selected for a subsidy from the wait list.

If the 16.9 point wait list effect is treated as part of the impact of the sub- 
sidy, then the full subsidy effect is $16.9+8.4=25.3$ percentage points from an average weekly subsidy of $\$ 45.62$. Assuming this was a 100 percent subsidy and noting that the employment rate of subsidy recipients while receiving the subsidy was 97.5 percent, this implies an employment rate of 72.2 percent in the absence of the subsidy, yielding an employment effect of 35 percent and an elasticity of 0.35 . If the 16.9 is treated as being due entirely to selection effects, then the corresponding elasticity estimate is 0.094 $[=8.4 /(97.5-8.4)]$. One drawback to generalizing from the study is that the subsidy was available only for use in day care centers, whereas most current programs provide vouchers that can be used in any paid arrangement. It is also not clear whether Kentucky is reasonably representative of the United States.

Meyers, Heintze, and Wolf (2002; hereafter MHW) use data from a sample of California AFDC recipients in four counties to analyze the determinants of receipt of a child care subsidy and the impact of subsidy receipt on employment. Individuals were randomly selected from AFDC administrative records in November 1992, interviewed about eighteen months later, and interviewed again eighteen months after the first interview. By the time of the second interview, 25 percent were no longer receiving welfare. Those still receiving welfare were eligible for subsidies under a variety of different programs, and assuming that the nonrecipients still had relatively low income they were also likely to have been categorically eligible for a subsidy under various California programs. MHW use a subsample of 903 single mothers who responded to the second interview to estimate probit models explaining whether a mother used any nonparental child care at the time of the survey and whether the mother received a child care subsidy conditional on using nonparental child care. These probits are estimated jointly in order to allow for the possibility that the unobserved determinants of subsidy receipt are correlated with the unobserved determinants of child care use. The predicted probability of subsidy receipt was computed from the estimated subsidy receipt probit for all mothers in the sample and was used as a regressor in an employment probit. One variable was excluded from the employment probit and included in the subsidy probit in order to identify the effect of subsidy receipt: an ordinal measure of the mother's knowledge of child care subsidy rules. The predicted subsidy probability has a positive coefficient in the employment probit with a $t$-ratio of 2.31. Simulations indicate that changing the probability of subsidy receipt from 0.0 to 0.5 would cause the employment probability to increase from .210 to .727 at the sample means of the other regressors. No information on the subsidy amounts or child care expenditures are provided, so an elasticity cannot be computed.

A potential problem with the evidence from this study is that there is no natural control or comparison group available. The implicit assumption is that mothers with little knowledge of child care subsidy rules are a valid 
comparison group for mothers with greater knowledge. Although this could be true, no evidence is presented to support the assumption. Mothers who are more motivated to work might also be more likely to seek information about subsidy programs. If such motivation is not captured by observed regressors, then the instrument is not valid and the comparison group is not comparable to the treatment group. ${ }^{30}$

Gelbach (2002) estimates the impact on employment of the implicit child care subsidy provided by free public kindergarten for five-year-old children. The structure of the subsidy is like Head Start: Free child care of a given quality is provided for a fixed number of hours, and child care outside school hours must be purchased by the family or supplied by informal providers. Gelbach notes the likely possibility that mothers with stronger unobserved tastes for work will be more likely to enroll a child in school at the earliest possible age, making subsidy receipt endogenous. To identify the effect of the subsidy, Gelbach exploits variation in quarter of birth of children and the fact that all states impose a date-of-birth requirement for entry to kindergarten. For example, if a child must have his fifth birthday by December 31 in order to enter kindergarten in the year in which he turns five, a mother whose child was born in the fourth quarter of the year will have access to the subsidy for that school year, whereas a mother whose child was born in the first quarter of the next calendar year will not, independent of labor supply preferences (assuming quarter of birth is exogenous). Gelbach uses quarter-of-birth dummies as instrumental variables for enrollment in public school. He uses data from the Public Use sample of the 1980 census (quarter of birth was not collected in the 1990 census) on 10,932 single mothers and 53,163 married mothers whose youngest child was aged five at the time of the census on 1 April $1980 .{ }^{31}$ Gelbach's instrumental variable estimates indicate that access to free public school increased the employment probability of single mothers whose youngest child was aged five by 5 percentage points at the interview date and by 4 percentage points during calendar year 1979. He also finds positive effects of about 3 on hours of work per week, 3.6 on weeks worked per year, $\$ 932$ on wage-salary income in 1979, and a 4 percentage point lower probability of receiving public assistance in 1979. All the estimates are significantly different from zero. The corresponding effects for married mothers whose youngest child was aged five were very similar for employment status and smaller for the other outcomes, compared to single mothers. Gelbach was not able to estimate the value of the subsidy, so the elasticity of employment with respect to the subsidy could not be computed.

30. A related but distinct conceptual issue is that the natural specification for the employment equation would include the actual subsidy receipt indicator, as in BB, not the predicted probability of subsidy receipt.

31. Gelbach reports that his instrumental variables (IV) strategy performed poorly for single mothers with a five-year-old child and another child younger than five. 
Gelbach's approach is creative and provides credible evidence of the impact of a child care subsidy on employment of mothers whose youngest child is five years old. However, it is unclear whether his results can be generalized to children younger than five. ${ }^{32}$ Gelbach cites evidence that employment responsiveness to the price of child care does not differ by age of the child, although there are of course differences in the level of employment by child age. He presents an extensive discussion and analysis of whether his results can be generalized to younger children and concludes that "While the estimates are not directly comparable to those for fiveyear-olds, they do make the case that large child care subsidies for parents of younger children are likely to have significant effects on maternal labor supply" (p. 320).

A final point about these three studies is that the drastic nature of the 1996 welfare reform may make the prereform results of these studies less relevant for predicting responses to current and future subsidies. Less emphasis was placed on moving welfare participants into employment before PRWORA. A mother might have been able to turn down a child care subsidy offer before PRWORA and remain out of the labor force without losing her welfare benefit. A mother who turned down a child care subsidy today would be more likely to lose eligibility for welfare. It seems plausible that a mother who is going to lose her welfare eligibility in any case would be likely to accept a subsidy offer and join the labor force. So the results of studies conducted in the pre-PRWORA environment will not necessarily be a good guide to behavior in the post-PRWORA era. ${ }^{33}$

Blau and Tekin (2002) use data from thirteen states in the 1997 National Survey of America's Families (NSAF) to estimate the impact of receiving a child care subsidy on employment, welfare participation, and other outcomes of single mothers with children under age thirteen. Subsidy receipt is measured by the respondent's report that a welfare or social service agency pays all or part of the monetary cost of child care for the family. Identification of the effect of subsidy receipt comes from the assumption that subsidies are rationed at the county level. Information on the county of residence is available for thirteen states that were oversampled in the NSAF. The employment and other outcome equations include the subsidy receipt indicator, state dummies, twenty-one county characteristics, lagged welfare and child care subsidy receipt, and demographic variables. A first-

32. There is also the issue of whether results from a universal subsidy are a reliable guide to the effects of a means-tested subsidy. Thirty-four percent of Gelbach's sample of single mothers whose youngest child was five years old received public assistance in 1979, and average 1979 wage-salary earnings of workers were $\$ 5,193$. Thus this is a relatively low-income sample that is likely to have been representative of mothers eligible for means-tested subsidies in 1980 , so his results do seem useful for predicting the impact of a similarly structured meanstested subsidy.

33. I thank Dan Black and Barbara Bergmann for emphasizing this point to me. 
stage equation for subsidy receipt includes county dummies, the lagged dependent variables, and demographic variables. Thus the identifying assumption is that there are no unobserved county-level determinants of employment; that is, county dummies can be excluded from the outcome equations. Ordinary least squares estimates show effects of subsidy receipt of 10.7 percentage points on employment, 8.0 points on school enrollment, and -1.4 points on welfare participation, with the first two significantly different from zero. Two-stage least squares (2SLS) estimates show effects of 4.6 percentage points on employment, 5.3 points on school enrollment, and 5.5 points on welfare participation, but none of the estimates are significantly different from zero. The standard errors are two to three times larger in the 2SLS estimates, making it difficult to draw any reliable conclusions from these estimates.

The data used by Blau and Tekin are more recent than in the other studies, but the identification strategy is problematic. They cannot determine whether any given family in their sample is eligible for a child care subsidy. Thus the differences in subsidy receipt by county may in fact reflect differences in eligibility and take-up behavior, as well as rationing by county agencies. The twenty-one county characteristics may help alleviate this problem, but there is no guarantee that the remaining county differences in subsidy receipt are exogenous. As in the MHW study, there is no natural comparison or control group.

\subsubsection{Inferences Based on Effects of the Price of Child Care}

More than a dozen studies have estimated the effect of the price of purchased child care on the employment of mothers. One of the motivations for this literature is to infer how child care price subsidies would affect employment decisions. Whether inferences about the effects of subsidies drawn from this literature are useful depends on several factors. First, if there are substantial costs to taking up a subsidy, either in the form of time costs required to negotiate the subsidy bureaucracy or psychic costs ("stigma") of participating in a means-tested program, then price effects on employment may not be a reliable guide to subsidy effects. Second, the price effects estimated in this literature are generally assumed to be linear, whereas most subsidies are nonlinear. As noted in section 7.4, nonlinearity of a subsidy does not affect the qualitative result that a child care price subsidy increases the incentive to be employed, but it could affect the magnitude of the employment effect. Thus estimates of linear price effects could be an unreliable guide to the effects of typical nonlinear subsidies. Third, issues of specification and estimation of econometric models of price effects could affect the inferences drawn from such effects. There is little basis for evaluating whether the first two issues are important in practice, so most of this subsection focuses on specification and estimation is- 
sues. ${ }^{34}$ The two key specification and estimation issues concern identification of the price effect and accounting for unpaid child care.

Table 7.7 summarizes results from studies of the effect of the price of child care on employment of mothers in the United States. ${ }^{35}$ Estimated price elasticities reported by the authors of the studies range from 0.06 to -1.26 . The studies differ in the data sources used and in sample composition by marital status, age of children, and income. Sample composition does not explain much of the variation in the elasticity estimates; the range of estimates is large within studies using the same sample composition. Differences in the data sources also do not appear to account for much variation in the estimates. There is substantial variation in estimates from studies using the same source of data (for example, Connelly 1992 versus Ribar 1992). Hence specification and estimation issues most likely play an important role in producing variation in the estimates.

The eleven studies listed in the upper panel of the table use very similar methods and are discussed as a group. These studies estimate a binomial discrete choice model of employment by probit or logit. The price of child care is measured by the fitted value from a child care expenditure equation estimated by linear regression on the subsample of employed mothers who paid for care. The expenditure equation is corrected for selectivity on employment and paying for care using either a standard approach (Heckman 1979) or a reduced-form bivariate probit model of employment and paying for care, following Maddala (1983) and Tunali (1986). In order to avoid relying exclusively on functional form for identification, some variables that are included in the child care expenditure equation are excluded from the employment probit in which the fitted value from the expenditure equation appears as a regressor. Also, some variables that are included in the probit selection equations are excluded from the child care price equation in order to help identify the selectivity effects. A Heckman (1979) selectivity-

34. The limited evidence on take-up of child care subsidies is discussed in section 7.5.4. Averett, Peters, and Waldman (1997) estimate a labor supply model that incorporates the DCTC by IV and a full information maximum likelihood (FIML) method that accounts for the kinks induced by the DCTC. The FIML estimate of the net wage effect on hours worked is about 50 percent larger than the IV estimate.

35. Other reviews of this literature can be found in Anderson and Levine (2000), Connelly (1991), and Ross (1998). Chaplin et al. (1999) review the literature on the effect of the price of child care on child care mode choice. Some studies are not included in the table because the elasticity of employment with respect to the price of child care was not estimated or reported. Some of the latter studies estimated an hours of work (or a marginal rate of substitution) equation instead of an employment equation (Averett, Peters, and Waldman 1997; Heckman 1974; Michalopolous, Robins and Garfinkel 1992). Others did not report enough information to determine the method of estimation or the elasticity (Connelly 1990; Kimmel, 1995). Michalopoulos and Robins (2000) use a pooled sample of Canadian and U.S. families, and Powell (1997) analyzes Canadian data. Michalopoulos and Robins report an elasticity of employment with respect to the price of child care of -.156 , and Powell's estimated elasticity is .38. See also Michalopoulos and Robins (2002) for a pooled analysis of Canadian and U.S. single mothers. 


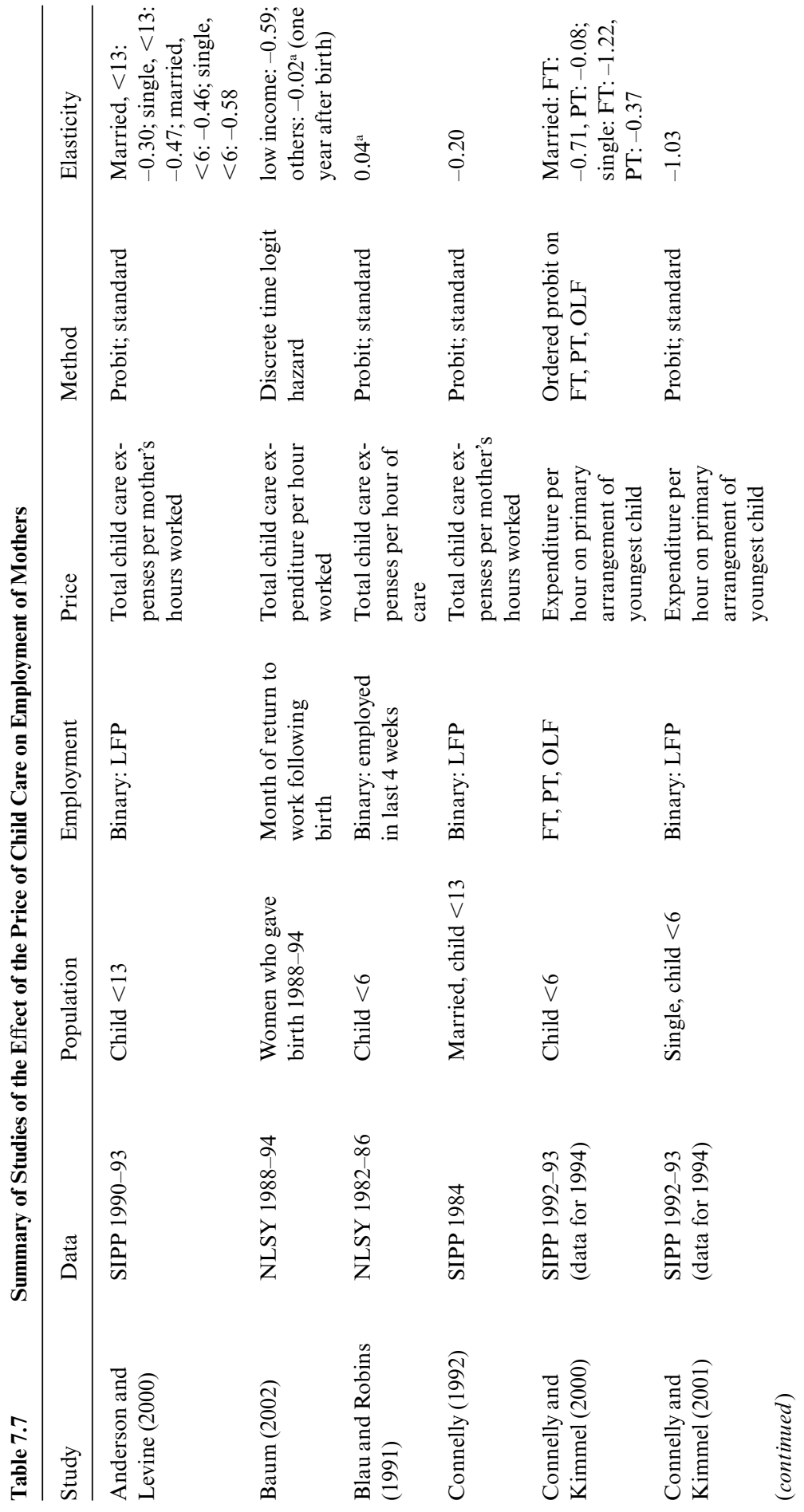




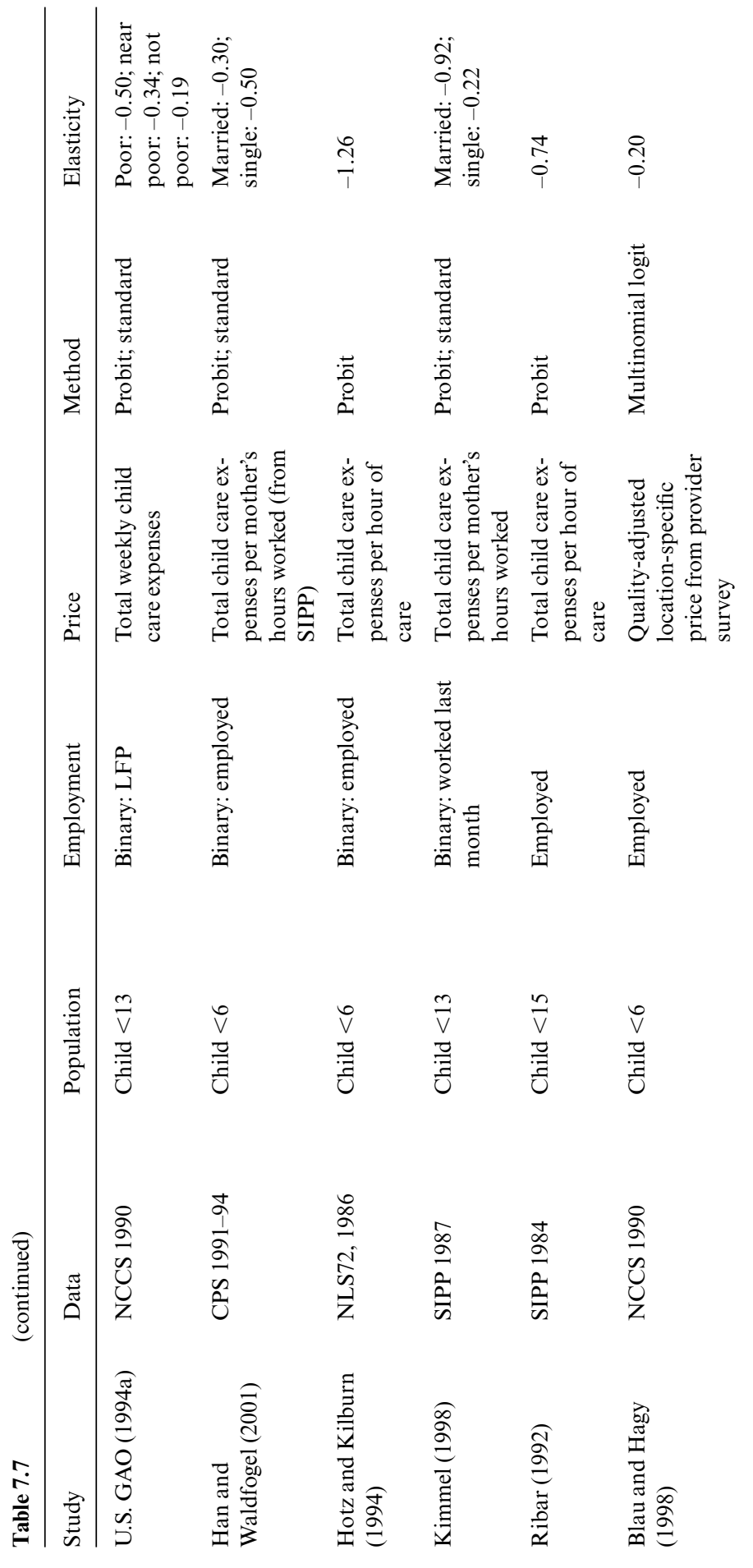




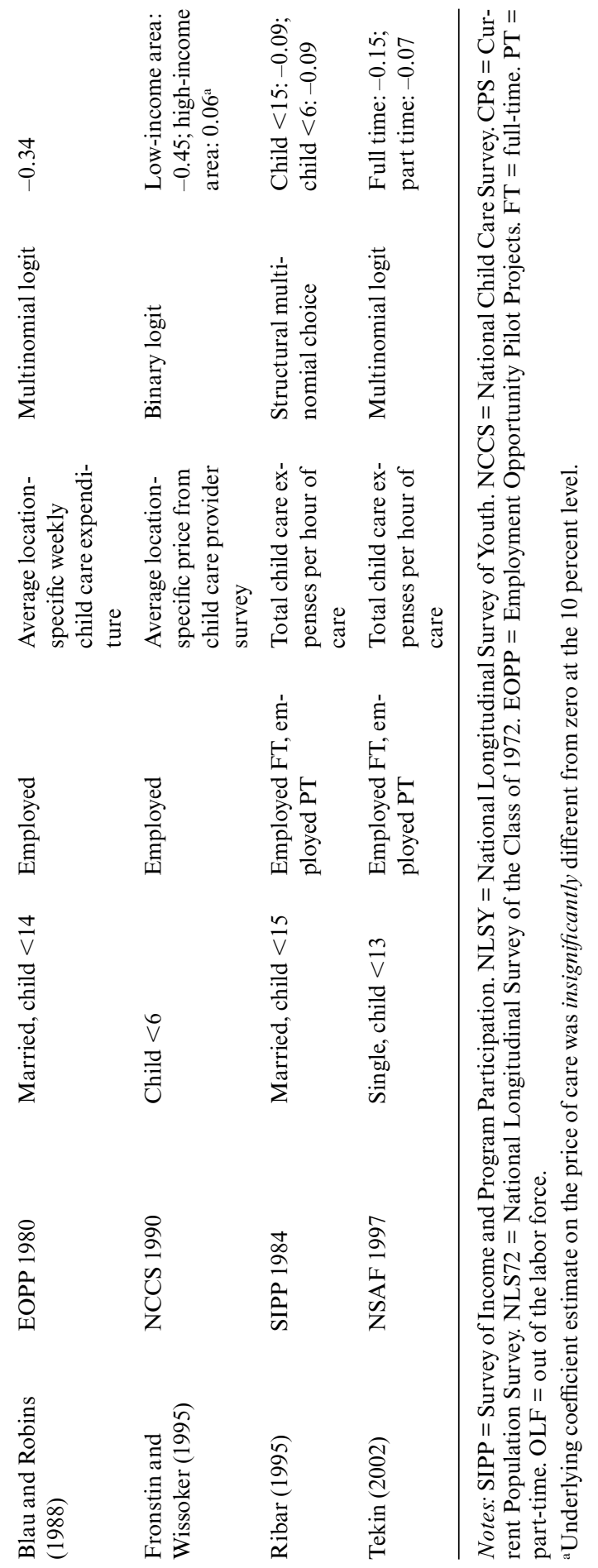


corrected wage equation is used to generate fitted values for the wage rate, which are included in the employment model. ${ }^{36}$

In order to provide a context for evaluating this empirical approach, it is useful to combine and extend the models developed in the analysis of informal care and quality in section 7.4. Recall that $H$ is hours of paid child care purchased in the market, $U$ is hours of unpaid child care provided by a relative, and child care is assumed to be required for every hour in which the mother works and for none of the hours in which she does not work, so $h=H+U$. The time constraints are $\ell+h=1$ for the mother, and $\ell_{r}+U$ $=1$ for the relative. The child development production function is respecified as $d=d\left(\ell q_{m}, H q, U q_{r}: \mathbf{X}_{1}\right)$, where $q_{m}\left(q_{r}\right)$ is the quality of child care provided by the mother (relative), $\mathbf{X}_{\mathbf{1}}$ is a vector of family and child characteristics that affect child development, and for simplicity $q_{m}$ and $q_{r}$ are assumed to be fixed. The utility function is $\mathrm{u}\left(c, \ell, \ell_{r}, d ; \mathbf{X}_{\mathbf{2}}\right)$, where $\mathbf{X}_{\mathbf{2}}$ is a vector of utility determinants. The budget constraint is $c=y+w h-p H$, where $p=\alpha+\beta q+f\left(\mathbf{X}_{3}\right)+\varepsilon_{p}, \mathbf{X}_{3}$ is a vector of price determinants other than quality, and $\varepsilon_{p}$ is a disturbance.

We are interested in estimating the effect of $p$ on the probability of employment, denoted $P(E)$. As noted in the previous section, there are several different outcomes (corner solutions) of the model in which the mother is employed. They differ by whether paid child care is used and whether unpaid child care is used. The price of child care affects the employment decision by its effect on the utility of these outcomes compared to the utility of not being employed. The general form of the conditional indirect utility functions (IUF) for each of the outcomes in the model is as follows:

\begin{tabular}{lcccc}
\hline Outcome & $\begin{array}{c}\text { Mother } \\
\text { Employed }\end{array}$ & $\begin{array}{c}\text { Relative } \\
\text { Care Used }\end{array}$ & $\begin{array}{c}\text { Paid } \\
\text { Care Used }\end{array}$ & $\begin{array}{c}\text { Indirect Utility } \\
\text { Function }\left(V_{\mathrm{i}}\right)\end{array}$ \\
\hline 1 & no & no & no & $V_{1}\left(y, q_{m}, X_{1}, X_{2}\right)+\varepsilon_{1}$ \\
2 & yes & yes & no & $V_{2}\left(y, q_{m}, w, q_{r}, X_{1}, X_{2}\right)+\varepsilon_{2}$ \\
3 & yes & yes & yes & $V_{3}\left(y, q_{m}, w, q_{r}, p, X_{1}, X_{2}\right)+\varepsilon_{3}$ \\
4 & yes & no & yes & $V_{4}\left(y, q_{m}, w, p, X_{1}, X_{2}\right)+\varepsilon_{4}$ \\
\hline
\end{tabular}

The $\varepsilon$ are disturbances representing variables unobserved by the investigator and are specified as additive for simplicity. The effect of interest $\partial P(E) /$

36. Exceptions to this general approach among the eleven studies include the following. Baum (2002) specifies the employment equation as a discrete-time monthly hazard model of return to work following birth of a child. Blau and Robins (1991) estimate the employment probit jointly with equations for the presence of a preschool age child and use of nonrelative care. Connelly and Kimmel (2000) estimate an ordered probit model for full-time employment, part-time employment, and nonemployment. Ribar (1992) estimates the employment equation jointly with equations for hours of paid and unpaid care. Hotz and Kilburn (1994) estimate their binary employment equation jointly with equations for use and hours of paid child care, child care price, and the wage rate. The wage, price, and nonwage income variables are not adjusted for taxes and subsidies in any of the studies listed in the table. 
$\partial p$ is derived from the model as $\partial[1-P(1)] / \partial p$, where $P(1)$ is the probability of choosing outcome 1 . To estimate this effect, a multinomial discrete choice model can be specified with functional form assumptions for the IUFs and disturbances, and empirical measures of the arguments of each IUF included as specified above. Depending on assumptions about the joint distribution of the disturbances, the model can be estimated by multinomial probit or logit, and the desired probability derivative can be computed. Two issues raised by this model are the interpretation and specification of a binomial employment equation and specification of the price $p \cdot{ }^{37}$

In the multinomial choice model the probability of not being employed is

$$
P(1)=\operatorname{pr}\left(V_{1}>V_{2}, V_{1}>V_{3}, V_{1}>V_{4}\right),
$$

and the desired effect $\partial[1-P(1)] / \partial p$ is derived by substituting the expressions for the $V_{i}$ s and computing the derivative. An equivalent expression for the probability of not being employed that could serve as a basis for a binary employment equation is

$$
P(1)=\operatorname{pr}\left(V_{1}>\max \left\{V_{2}, V_{3}, V_{4}\right\}\right)=\operatorname{pr}\left(V_{1}>\sum_{i=2}^{4} D_{i} V_{i}\right),
$$

where $D_{i}=1$ if $V_{i}>V_{j}, i, j=2,3,4, i \neq j$, and $D_{i}=0$ otherwise. The binary variables $D_{i}$ "dummy out" regressors that are not relevant to the mother's employment decision. For example, if the mother's highest-utility employment outcome $\left(\max \left\{V_{2}, V_{3}, V_{4}\right\}\right)$ does not involve paid care, then the $V_{i}$ functions on the right-hand side of the inequality that include $p$ will be dummied out. Thus, estimating a binomial employment equation based on this model requires knowing which of the employment outcomes 2, 3, and 4 provides the highest utility for each mother. For mothers who choose not to be employed, we do not know which of the employment options would have provided her the highest utility (i.e. we do not observe the values of $D_{i}$ ). For employed mothers we observe these outcomes, but whether the best employment option involves paid care, relative care, or both is a choice made by the mother. Consistent estimates of the parameters of the employment equation cannot be obtained without accounting for this choice, regardless of the distribution of the disturbances. The multinomial choice model accounts for this choice, but the binomial model does not.

37. Another issue is determining whether a mother has the option of unpaid child care by a relative. If we observe a mother using unpaid relative care then we know this option was part of her choice set. If she does not use unpaid relative care, it is possible to ask her whether such care was available, and some surveys have done this (e.g., the National Child Care Survey). The reliability of responses to such questions is unknown, but they could be used to determine the choice set: If a mother indicates that relative care is unavailable, options 2 and 3 can be eliminated from her choice set. Alternatively, it can be assumed that unpaid relative care is available to every mother, with a "relative" of last resort being self-care by the child, an option with presumably very low quality. 
To illustrate this point, suppose the disturbances are independently and identically distributed as Type I Extreme Value, yielding the multinomial logit functional form for the choice probabilities. Suppose we assume that the best employment option for all mothers is number 4 , in which only paid child care is used. The likelihood function contribution for a mother who chooses option 1 (not employed) under this assumption would be

$$
P(1 \mid 1 \text { or } 4)=\frac{e^{\overline{V_{1}}}}{e^{\overline{V_{1}}}+e^{\overline{V_{4}}}}
$$

where $\bar{V}_{i}=V_{i}-\varepsilon_{i}$. The correct likelihood contribution for a mother for whom option 4 is in fact the best employment alternative is

$\mathrm{P}(1)=\mathrm{P}(1 \mid 1$ or 4$) \mathrm{P}(1$ or 4$)=\frac{e^{\overline{V_{1}}}}{e^{\overline{V_{1}}}+e^{\overline{V_{4}}}} \cdot \frac{e^{\overline{V_{1}}}+e^{\overline{V_{4}}}}{\sum_{i=1}^{4} \bar{V}^{\overline{\bar{V}_{i}}}}=\frac{e^{\overline{V_{1}}}}{\sum_{i=1}^{4} e^{\bar{V}_{i}}}$.

If option 4 was in fact the best employment option for every mother, then without loss of generality we can set $\bar{V}_{2}=\bar{V}_{3}=-\infty$. In this case the second term in the expression following the second equality sign is equal to one, and $\mathrm{P}(1 \mid 1$ or 4$)$ is the correct likelihood contribution. If not, then the wrong likelihood contribution is used, resulting in inconsistent estimates. For a mother for whom option 4 is not the best employment choice, $\mathrm{P}(1 \mid 1$ or 4$)$ is obviously not the correct likelihood contribution. It is not possible to determine the nature of the bias caused by this misspecification, since the model is nonlinear and there is no analytic expression for the estimator. If unpaid care was an infrequent choice, ignoring it might cause little bias. But the data show that unpaid care is a common choice, particularly among low-income mothers and mothers with young children (see table 7.6). Specifying an employment model under the assumption that paid care is always the relevant nonmaternal child care option is thus a potentially serious error, leading to inconsistent parameter estimates. This was noted by Heckman (1974) in one of the earliest economic studies of child care but has been ignored in many recent analyses.

The other main issue is how to measure the price of child care. The first eleven studies listed in table 7.7 all use the fitted value from a selectioncorrected child care expenditure ${ }^{38}$ equation estimated on the subsample of employed mothers who use paid care. This approach is intended to deal with the facts that expenditure on child care is not observed for mothers who do not pay for care, and observed expenditure for mothers who pay is endogenous if the quality of paid care affects price and if quality is a choice variable. The demand function for the quality of paid care can be derived by solving the first order conditions conditional on paying for care:

38. Expenditure is measured per hour of paid care or per hour of the mother's work, except in U.S. General Accounting Office (1994a), in which it is expenditure per week. 


$$
q=q\left(X_{1}, X_{2}, y, q_{m}, w, q_{r}, p, \varepsilon_{i}\right) .{ }^{39}
$$

Substitute this quality demand function into the price equation $p=\alpha+\beta q$ $+f\left(X_{3}\right)+\varepsilon_{p}$, and solve to obtain a reduced-form price function

$$
p=p\left(X_{1}, X_{2}, X_{3}, y, q_{m}, w, q_{r}, \alpha, \beta\right)+\varepsilon_{p}^{*},
$$

where $\varepsilon_{p}^{*}$ is a function of $\varepsilon_{p}$ and $\varepsilon_{i}{ }^{40}$ For simplicity ignore the issues discussed in the preceding paragraphs, and specify a binomial employment equation of the form

$$
P(E)=P\left(p, X_{1}, X_{2}, y, q_{m}, w, q_{r}, \varepsilon_{i}\right) .
$$

The employment equation includes $p$ and excludes $X_{3}$, $\alpha$, and $\beta$, and the latter three variables appear in the reduced-form price equation. If $X_{3}$ contains at least one variable not also included in $X_{1}$ or $X_{2}$, or if $\alpha$ or $\beta$ varies across mothers and can be measured, then the price effect in the employment equation is identified by exclusion restrictions. Researchers have typically used child care regulations, average wages of child care workers, and other factors that vary across geographic locations as identifying variables in $X_{3}$, under the assumption that such variables affect household behavior only insofar as they affect the price of child care. Some studies have also used variables such as the number of children by age for identification.

If the unobserved factors that influence employment and child care behavior $\left(\varepsilon_{i}\right)$ are correlated with the unobserved determinants of the price of care $\left(\varepsilon_{p}\right)$, then estimating the reduced-form price equation on a sample of mothers who are employed and pay for care yields biased estimates. Most researchers who use this approach have recognized this problem and as noted above have specified reduced-form employment and pay-for-care equations that are used to correct the child care price equation for selection effects in a two-stage estimation. However, the model implies that there are no theoretically justified exclusion restrictions to identify the selection effects: the price function is a reduced form, so it contains all of the exogenous variables in the model. Substitute the reduced-form price equation into the employment equation and solve to obtain

$$
P(E)=P^{*}\left(X_{1}, X_{2}, X_{3}, y, q_{m}, w, q_{r}, \alpha, \beta, \varepsilon_{i}, \varepsilon_{p}\right),
$$

Where $P^{*}$ denotes the reduced-form employment equation. This has the same determinants as the price equation. The same result holds when a reduced-form pay-for-care equation is derived, conditional on employment. Hence the only basis for identification of a child care price equation using

39. This must be done separately for each outcome in which paid care is used. If unpaid care is not used jointly with paid care (outcome 4), then $q_{r}$ is omitted from the demand function.

40. If the mother's wage is thought to be endogenous, its determinants can be substituted, since we are not particularly interested in the wage effects in this equation. 
consumer expenditure data in a manner consistent with economic theory would be functional form or covariance restrictions (i.e., assume that the unobserved factors that influence employment and child care behavior are uncorrelated with the unobserved determinants of the price of care).

The estimated elasticity of employment with respect to the price of child care ranges from 0.04 to -1.26 in the first eleven studies listed in table 7.7. Without a detailed examination of specification and estimation differences across the studies along the lines of Mroz (1987), it is difficult to explain why these estimates are so varied. It is possible that some of this variation is due to the two problems discussed here: treating paid child care as if it were the best option for all mothers, and inappropriate exclusion restrictions to identify the child care price equation. Different identification restrictions are used in each study, possibly leading to different degrees of bias. Different data sources containing different proportions of mothers who use paid care are used in each study, and the bias caused by treating paid child care as if it were the best option for all mothers is likely to depend on this proportion.

Of the five studies in the lower part of the table, Fronstin and Wissoker (1995) differ from the standard approach in measuring the price of care from a survey of child care providers rather than from consumer expenditure. This approach will be discussed below. They specify a binary employment equation, estimated by logit, based on the standard implicit assumption that paid care is always the best option.

The other four studies in the lower panel of table 7.7 use variants of the multinomial choice framework discussed above. Ribar (1995) specifies a structural multinomial choice model with a quadratic utility function in consumption, hours of work, and hours of paid care. The discrete outcomes are full-time employment with unpaid care, full-time employment with paid care, part-time employment with unpaid care, part-time employment with paid care, and no employment. The standard approach of imposing arbitrary exclusion restrictions on reduced-form employment and payment equations is used. ${ }^{41}$ However, paid child care is not treated as if it was the best option for all mothers: The price of child care influences behavior by affecting the utility of the two options in which paid care is used, consistent with the theory described above. Two disturbances are incorporated, allowing the unobserved determinants of employment and child care to be correlated.

Tekin (2002) estimates a discrete choice model with outcomes defined by cross-classifying employment status (full-time, part-time, not employed) with indicators for use of paid child care conditional on employment and

41. Ribar specifies an equation for total expenditure rather than expenditure per hour and allows it to be nonlinear in hours of care and to contain a fixed component. These equations are estimated jointly with the child care expenditure equation by FIML instead of by the usual two-stage approach. 
receipt of a child care subsidy conditional on employment and use of paid care. A multinomial logit model with a discrete random effect accounts for the possibility of correlation in the disturbances across the discrete choices (Mroz 1999). A child care expenditure equation identified by state dummies (which are excluded from the discrete choice model) is estimated jointly with the discrete choice model. Similar to Ribar, Tekin's approach does not impose the assumption that paid care is always the best option for an employed mother. Like the studies in the upper panel of table 7.7, Tekin uses consumer expenditure data to measure the price of child care, but unlike those studies he does not impose arbitrary identification restrictions to identify selection models of child care payers. Rather, he imposes a covariance restriction: The unobserved determinants of the price of care are assumed to be independent of the unobserved determinants of employment and child care decisions.

Blau and Hagy (1998) specify a multinomial choice model with categories defined by cross-classifying binary indicators of employment and paying for care with a four-way classification of mode of care (center, family day care, other nonparental, and parent). As in Ribar (1995) and Tekin (2002), the price of child care affects behavior only by affecting the utility of outcomes involving paid care, so paid child care is not treated as if it was the best option for all mothers. The model is estimated by multinomial logit jointly with equations for hours of work, hours of child care, and several other continuous outcomes. A discrete random effect is incorporated to account for the possibility of correlation in the disturbances across the discrete choices and between the disturbances in the discrete and continuous outcomes.

As in Fronstin and Wissoker (1995), the price of child care is derived from a survey of day care centers and licensed family providers, conducted in the same geographic locations as the survey of consumers. Blau and Hagy use these data to estimate regressions of the form

$$
p_{i k}=\alpha_{j}+\beta q_{i j}+\gamma X_{3 i j}+\varepsilon_{p i j},
$$

for provider $i$ in site $j$. These are estimated separately for centers and family day care homes. Quality is measured by factors thought to influence the quality of care, such as group size, teacher qualifications, provider goals, and staff turnover. Other provider characteristics such as age, race, and hours of operation are included in $X_{3 i j}$. The slope coefficients ( $\beta$ and $\gamma$ ) are restricted to be the same across sites, but the intercepts $\left(\alpha_{j}\right)$ are allowed to be site-specific. The price assigned to each household in site $j$ for a given mode of care is $\hat{p}_{j}=\hat{\alpha}_{j}+\hat{\beta} \bar{q}+\hat{\gamma} \bar{X}_{3}$, where a hat indicates an estimated parameter and a bar indicates the overall sample mean. Hence the only source of variation used is geographic variation in the intercept of the price function. This can be thought of as a quality-adjusted price, where the sample mean quality has been assigned to all observations. This approach 
avoids selection and identification problems inherent in the use of consumer child care expenditure data to measure the price of care, and allows for observed differences across locations in quality and other factors. ${ }^{42}$ However, it does not allow for the possibility of unobserved heterogeneity across locations in the average quality of child care. If such unobserved heterogeneity is present (after controlling for a large number of observed factors in $q$ and $X$ ), then $\hat{\alpha}_{j}$ (and therefore $\hat{p}_{j}$ ) would be correlated with the disturbances in the multinomial choice model, since those disturbances incorporate unobserved preferences for quality. Fronstin and Wissoker's approach to measuring the price of child care can be though of as a special case of this approach in which the restrictions $\beta=\gamma=0$ are imposed.

Blau and Robins (1988) estimate a multinomial choice model derived from the framework described above, with two modifications: They assume that paid and unpaid care cannot be used simultaneously, and they allow the employment status of the relative to be a choice variable. The model was estimated by multinomial logit, but the price of child care was included in all of the outcomes in which the mother is employed instead of only those in which paid care is used. This is inconsistent with the theory described above and is equivalent to assuming that paid care is always the best option. Blau and Robins used the site-specific average weekly child care expenditure as a measure of the price of care for all families in a given site. This is equivalent to the Fronstin-Wissoker approach, using weekly instead of hourly price, and using consumer expenditure instead of provider price.

The studies that are most consistent with an underlying framework in which informal care is dealt with appropriately are Blau and Hagy (1998), Ribar (1995), and Tekin (2002). These studies produce estimates of the elasticity of employment with respect to the price of child care at the lower end of the range (in absolute value) in table 7.7: -0.09 in Ribar, -0.15 in Tekin, and -0.20 in Blau and Hagy. Blau and Hagy repeated their analysis using consumer expenditure data to measure the price of child care in place of the provider survey data, and they estimated an elasticity of -0.06 in this case. This could explain why Ribar's and Tekin's estimates are smaller than those of Blau and Hagy, since Ribar and Tekin used consumer expenditure data to measure price. It is risky to generalize from only three studies, but the fact that the studies that accounted for informal care in ways consistent with economic theory produced small elasticities suggests that the true elasticity may be small.

The elasticity of employment with respect to the price of child care may

42. This approach could not be used to assign prices for other nonparental care. Such care consists mainly of babysitters, small unlicensed family day care, and relatives, and providers of this type were not sampled in the provider survey. The consumer expenditure data were used to estimate a price equation for this mode, not corrected for selection. 
differ across groups. Ribar (1995) uses a sample of married mothers and Blau and Hagy use a sample with married and single mothers, dominated by the former. If the elasticity of employment with respect to the price of child care is different for married and single mothers, then the evidence from these two studies would not be a good guide to price effects for single mothers. However, Tekin's estimates for single mothers are similar to those of Ribar and Blau and Hagy. Kimmel's (1998) results indicate quite different elasticities for married and single mothers, but Anderson and Levine (2000) and Connelly and Kimmel (2000) produce estimates that are closer for the two groups. If the elasticities differ substantially by income, then estimates for random samples of the population, as in Blau and Hagy (1998), Ribar (1995), and Tekin (2002), could be misleading if applied to the lowincome population. Estimates produced by Anderson and Levine (disaggregated by education of the mother; not shown in table 7.7), Baum (2002), Fronstin and Wissoker (1995), and U.S. General Accounting Office (1994a) all show larger elasticities for low-income groups. This suggests that the true elasticity for low-income mothers could be larger than the estimates from Blau and Hagy, Ribar, and Tekin.

Four studies provide estimates of the effect of the price of child care on hours of work by the mother, conditional on employment. Averett, Peters, and Waldman (1997) report an uncompensated labor supply elasticity with respect to the price of child care of -.78 from their kinked budget constraint model for annual hours of work. Blau and Hagy (1998) estimate the price effect on weekly hours of work separately by the mode of child care used and find uncompensated effects of 1.3, 2.0, and -1.8 respectively for users of centers, family day care, and other nonparental care. These imply elasticities at the sample means of $0.06,0.08$, and -0.05 , respectively. Michalopoulos, Robins, and Garfinkel (1992) report an elasticity of annual hours worked with respect to the price of child care of essentially zero based on a structural model with a Stone-Geary utility function. Baum (2002) also finds small elasticities, not significantly different from zero. The large elasticity estimated by Averett, Peters, and Waldman (1997) compared to the much smaller estimates of the other studies could be a result of the use of the kinked budget constraint method, which imposes a substitution effect with a sign consistent with economic theory whether or not this is consistent with the data (MaCurdy, Green, and Paarsch 1990).

\subsubsection{Evidence on Other Effects of Subsidies and Price of Child Care}

\section{Quality of Child Care}

As discussed in section 7.4, economic theory does not predict the sign of the effect of the price of child care on the quality of care demanded. The literature contains only two studies of the effect of the price of child care on 
demand for quality: Blau and Hagy (1998) and Hagy (1998). ${ }^{43}$ Blau and Hagy estimate consumer demand functions for inputs to the production of quality: staff-child ratio and group size in the child care arrangement, and whether the provider has received any training in early childhood care and education. Hagy focuses exclusively on staff-child ratio. Developmental psychologists argue that the quality of a child care arrangement is best measured by the nature of the interactions between the provider and child and aspects of the curriculum, as measured by instruments such as the ECERS-ITERS described above (see note 17). Staff-child ratio and so forth are inputs to producing quality, although some recent evidence suggests that the productivity of these inputs is modest at best (Blau 1997, 1999, 2000). So these are not the best measures of quality, but they are the only ones available that can be matched to a price.

Blau and Hagy use the price measure described above, $\hat{p}_{j}=\hat{\alpha}_{j}+\hat{\beta} \bar{q}+\hat{\gamma} \bar{X}_{3}$. Price effects on demand for the inputs were estimated separately for users of centers and family day care, and separately by whether the mother was employed, accounting for self-selection into these groups. The results for users of day care centers show a negative effect of $\hat{p}_{j}$ on group size, essentially zero impact on staff-child ratio, and a positive effect on the probability of having a trained provider. These results imply that $\alpha$-subsidies that reduce $\hat{p}_{j}$ would lead to demand for larger groups and less provider training by center users, leading to lower quality of child care. Price effects on hours of care demanded per week were negative, indicating that when price falls consumers substitute toward quantity and away from quality. As the quality-constant price falls, consumers purchase more hours of care, raising the implicit price of quality. This leads to a decrease in demand for quality. For users of family day care, the price effects were positive on group size, negative on staffchild ratio, and positive on training. In this case $\alpha$-subsidies that reduce $\hat{p}_{j}$ would lead to demand for smaller groups, a larger ratio of staff to children, and less provider training, producing an uncertain effect on quality depending on the relative productivities and elasticities of demand for the inputs.

Hagy (1998) specifies a price regression of the form $p_{i j}=\alpha+\beta_{1 j} q_{i j}+$ $\beta_{2 j} q_{i j}^{2}+\gamma X_{3 i j}+\varepsilon_{p i j}$ for provider $i$ in site $j$, where quality $q$ is measured by the staff-child ratio. The model is quadratic in quality and allows $\beta$ to vary by site instead of $\alpha$ as in Blau and Hagy. The implicit marginal price of staffchild ratio facing a consumer in site $j$ is $\partial p_{i j} / \partial q_{i j}=\beta_{1 j}+2 \beta_{2 j} q$, where $q$ is the staff-child ratio in the arrangement used by the consumer. This implicit marginal price is included as a regressor in a model to explain consumer demand for staff-child ratio. Recognizing that the marginal price depends on

43. Some studies have estimated price or subsidy effects on other attributes of child care such as choice of mode, hours of care, and travel time to the arrangement. These are interesting, but of less policy relevance than effects on employment and child care quality, and they are not discussed here. See Blau and Hagy (1998) and Chaplin et al. (1999) for examples and references to other studies. 
quality, Hagy instruments the marginal price with a set of site dummies, thus using only geographic variation to identify the price effect, as in Blau and Hagy. The demand for staff-child ratio is estimated only for users of day care centers, accounting for self-selection into this mode of care. The effect of the price is positive and significantly different from zero, but very small in magnitude, with an implied price elasticity of .017.

\section{Child Development}

There are no studies of the effect of the price of child care or child care subsidies on child development outcomes. However, there is a substantial literature that evaluates the child development effects of Head Start and other early intervention programs. ${ }^{44}$ Since these programs can be interpreted as child care subsidies, their effects on child development are discussed here. This large literature has been reviewed by Karoly et al. (1998), Barnett (1992, 1995), Currie (2001), and Waldfogel (2002) among others, and is summarized briefly here. Karoly et al. (1998, p. xiii) conclude that "in some situations, carefully targeted early childhood interventions can yield measurable benefits in the short run and that some of those benefits persist long after the program has ended." This conclusion is based on evaluations of nine early intervention programs with randomized assignment to treatment, including the well-known Perry Preschool, Carolina Abecedarian, and Infant Health and Development projects. Most of the programs produced short-run gains in IQ, but few have produced IQ gains that have lasted past age twelve. However, short-run improvements in academic achievement caused by the programs did persist in most of the programs through the latest age at which achievement was measured (age twenty-one in the Abecedarian project ${ }^{45}$ ). The Perry Preschool evaluation followed the children longer than any of the other intervention evaluations and has found substantial improvements through age twenty-seven in high school graduation, crime and delinquency, income, and welfare participation. No effects on grade repetition and teen pregnancy were found. The mechanisms through which these effects occur are not well understood, because it seems clear that they are not a result of long-run improvements in IQ.

There have been many evaluations of Head Start, but they have been hampered by two factors: None have been based on randomized assignment, and Head Start is not a single program but is rather an umbrella for a large number of programs that vary in design and quality while presumably meeting the main requirements for a Head Start program (Karoly et al. 1998). ${ }^{46}$

44. I am not aware of any studies of the effects of Head Start or other early education programs on maternal employment.

45. See Campbell et al. (2001, 2002) for age twenty-one results in the Abecedarian study.

46. A recent report of the Advisory Committee on Head Start Research and Evaluation (1999) strongly recommended a randomized assignment evaluation of Head Start. A random assignment evaluation of Head Start is now under way, with field work having begun in 2002. 
Evaluations of Head Start have almost uniformly found substantial positive short-run impacts on IQ that have subsequently faded out within a few years after exit from the program. About half of the Head Start evaluations found short-run positive effects on reading and mathematics achievement that faded out within a few years, and the others found no short-run effects. However, Head Start evaluations that have examined effects on grade retention (seven), special education (four), and high school graduation (one study) have sometimes found positive effects on these outcomes (Barnett 1995).

The only Head Start evaluation that has found effects on cognitive ability that have not faded out over time is Currie and Thomas (1995), who found this result for white children but not black children. Like other Head Start evaluations, theirs was not based on a randomized design. But unlike other evaluations they were able to control for at least some potentially confounding unobserved factors by exploiting the facts that the National Longitudinal Survey of Youth (NLSY) contains data on multiple children in the same families, and there are substantial numbers of families in which at least one child attended a Head Start program and at least one child did not. Using a fixed effects estimator that identifies the effect of Head Start only by within-family differences between siblings who did and did not attend Head Start, Currie and Thomas find substantial positive short-run effects on cognitive ability (the Peabody Picture Vocabulary Test) for whites and blacks that do not fade out for whites but do for blacks; no short- or long-run effects on grade retention for blacks, but a substantial positive effect for whites that fades only a bit over time; and positive shortrun effects on measles immunization that fade out for both races. Currie and Thomas note that their method relies on the assumptions that assignment of children to Head Start within families is uncorrelated with childspecific unobservables and that there are no spillover effects of Head Start attendance by one child on other children in the family. The first assumption would be valid if, for example, Head Start slots were rationed by some randomized method that did not favor the siblings of children who had already attended Head Start, or if family income changed over time in a way that was unrelated to child-specific factors and led to one child in the family being eligible for the program and another not being eligible. They argue and present evidence that if child-specific unobservables and spillover effects matter, they will tend to bias the fixed effects estimates of the effect of Head Start toward zero. ${ }^{47}$

47. Garces, Thomas, and Currie (2002) report positive long-run effects of Head Start for both races using a within-family estimator with data from the Panel Study of Income Dynamics. Currie and Thomas (2000) present evidence that the fade-out effects observed for blacks may be due to the fact that black children attend lower-quality schools than whites. Currie and Thomas (1999) find positive effects of Head Start on cognitive outcomes for children of native-born Hispanic mothers but not for children of foreign-born Hispanic mothers. They do not examine fade-out in this paper. 
An important issue concerning early childhood interventions that involve a child care component is whether the benefits of the intervention exceed the costs. The interventions tend to be expensive relative to typical market child care because they are designed to provide very high-quality services to help overcome the developmental disadvantages faced by lowincome children. But the benefits are potentially large as well, if academic achievement, higher earnings, and lower welfare participation are permanent results of the intervention. The data needed to perform a credible and thorough benefit-cost analysis of Head Start and other early intervention programs do not exist. Cost data are readily available, but many of the benefits are intangible, and others that could in principle be quantified are spread over long time periods and require data that have not been collected. Karoly et al. used data from an analysis by Barnett (1993a, 1995) to perform a cost savings analysis of one early intervention program, the Perry Preschool Project. This analysis does not attempt to measure all of the benefits of the program to the participants or society, but rather tries to determine whether the program results in direct savings to the government that (in present value terms) exceed the cost of the program to the government. If the answer is yes, government funding of the program can be justified purely as a way for the government to reduce net expenditures without even considering other possible benefits of the program. This is a conservative approach to evaluating a program, but Karoly et al. argue that it is the only approach available given data limitations, and even for this approach the data needed are available for only one program. If savings to the government do not exceed the cost of the program, this does not necessarily mean that funding the program is not worthwhile.

The following figures illustrate the calculations by Karoly et al., based on Barnett's figures using data through age twenty-seven of the participants, expressed in 1996 dollars discounted at 4 percent to the date of birth of the child:

\begin{tabular}{lccr}
\hline & \multicolumn{3}{c}{ Government Savings } \\
\cline { 2 - 4 } Item & $\begin{array}{c}\text { Program } \\
\text { Cost }\end{array}$ & $\begin{array}{c}\text { Through } \\
\text { Age 27 }\end{array}$ & $\begin{array}{c}\text { Projected, } \\
\text { Ages 28-65 }\end{array}$ \\
\hline Cost of preschool, ages 3-4 & $\$ 12,148$ & & \\
Reduced special education costs & & $\$ 6,365$ & \\
Increased taxes on earnings & & $\$ 3,451$ & $\$ 3,115$ \\
Decreased welfare payments & & $\$ 1,968$ & $\$ 341$ \\
Decrease in criminal justice cost & $\$ 7,378$ & $\$ 2,817$ \\
Total & $\$ 12,148$ & $\$ 19,162$ & $\$ 6,273$ \\
\hline
\end{tabular}

These calculations do not place any value on the decrease in tangible and intangible losses to crime victims, or the increased earnings of the program participant. Even this very conservative approach that prices out only tan- 
gible cost savings to the government leads to the conclusion that the Perry Preschool Project was a highly worthwhile investment.

\section{Subsidy Take-Up}

Meyers and Heintze (1999) examine the use of child care subsidies in a sample of current and former welfare recipients in four counties of California in 1995. In their sample, 16 percent of employed mothers received a child care subsidy, 30 percent of mothers enrolled in education or training programs received a subsidy, and 34 percent of mothers in neither activity received a subsidy (including Head Start). The public subsidy system for child care in California was quite complex prior to PRWORA, with at least seven different subsidy programs. When mothers were asked why they did not receive subsidies from the programs for which they appeared to be eligible, the majority response for all three employmentrelated subsidy programs, one out of two education-and-training-related subsidies, and one out of two child-education subsidies was that they were not aware of the program. The majority response for the other two subsidy programs was "aware of the program but did not apply." The acceptance rate for mothers who applied averaged 72 percent across all programs.

Fuller et al. (1999) estimate a model of the child care subsidy take-up decision of mothers enrolled in TANF using data collected in San Francisco, San Jose, and Tampa in $1998 .{ }^{48}$ Of the women in their sample who used any nonmaternal child care, 37-44 percent received a subsidy, depending on the site. Presumably, all of the women in this sample were categorically eligible for a child care subsidy, but there is no way to determine whether the mothers not receiving a subsidy were rationed out or did not take up the subsidy offer. A regression analysis showed that a woman's knowledge of child care subsidy rules and participation in a TANF-sponsored job search class were positively associated with receiving a subsidy.

\section{Welfare Receipt}

Connelly and Kimmel (2001) use 1994 data on single mothers from the SIPP to estimate the impact of the price of child care on AFDC participation. Using the standard approach to measuring price, they find an elasticity of AFDC participation of .55 with respect to the price of child care from an ordinary probit model, and an elasticity of .28 from a probit model estimated jointly with an employment probit.

Tekin (2001) estimated the effect of the price of child care on enrollment in TANF using data on single mothers with children aged zero to thirteen from the 1997 NSAF. He specified a multinomial model of employment, welfare participation, and payment for child care. Using the estimation ap-

48. See Fuller et al. (2000) for a complete description of the data. 
proach in Tekin (2002) described above, the estimated elasticity of TANF enrollment with respect to the price of child care was .098.

\subsection{Current Policy Issues and Reform Options}

\subsubsection{Current Policy Issues}

Three issues arise frequently in recent discussions of child care policy: insufficient funding for subsidies to meet welfare reform goals, inequitable distribution of subsidies, and concern about the quality of child care purchased with subsidies.

\section{Insufficient Funding}

It is estimated that despite spending all of the available federal and required state matching CCDF funds, as well as using up to a billion dollars of their TANF block grants on child care, states provided subsidies to only 15 percent of eligible children in 1998 (Administration for Children and Families 1999). States face considerable pressure and incentives from the federal government to reduce welfare rolls, and it is likely that the majority of subsidy recipients are current or former welfare participants. ${ }^{49}$ It is unclear whether the current level of child care subsidy funding is sufficient to help states meet their specific welfare reform targets for employment, but it seems likely that demand for subsidies by eligible low-income families who are not connected to the welfare system exceeds the supply of subsidies available to such families with the current level of funding. ${ }^{50}$

\section{Inequity}

Before the welfare reform of 1996, the existence of many different child care subsidy programs with varying eligibility rules and fee schedules created considerable horizontal inequity in the distribution of subsidies. Many observers noted the fragmentation and lack of coordination that resulted from the proliferation of subsidy programs with varying goals and

49. Piecyk, Collins, and Kreader $(1999,11)$ report that 68 percent of children receiving child care subsidies through state-administered programs in Maryland in January 1998 were current or former welfare recipients, and the corresponding figure for Illinois was 84 percent. National data on the characteristics of subsidy recipients are not available. CCDF regulations require states to stipulate a plan for spending 70 percent of subsidy funds on current and former welfare recipients.

50. See Besharov (2002) and Mezey et al. (2002) for alternative views of the adequacy of current child care subsidy funding. It would be useful to know how much additional funding would be required in order to serve all eligible children. A naïve estimate would be about $\$ 36$ billion $(1998$ dollars $)=(6.399 / .15)-6.399$ : the 1998 level of CCDF funding divided by the estimated proportion of eligible children served, minus the 1998 level of funding. However, this ignores issues such as whether all eligible families would want a subsidy, whether the average expenditure per child would change if all eligible children were served, and whether states would change their subsidy rules if more funding was available. 
rules (Barnett 1993b; Gomby et al. 1996). The consolidation of subsidy programs mandated by PRWORA helped to reduce this problem but did not eliminate it (Adams, Snyder, and Sandfort 2002). For example, there is often little coordination at the local level between Head Start and other child care subsidy programs, so some families may receive both a Head Start and a CCDF subsidy and others receive neither. Many observers call for closer coordination between Head Start and other child care subsidy programs (Schumacher, Greenberg, and Lombardi 2001).

\section{Child Care Quality}

Most of the child care subsidies provided under the CCDF are in the form of certificates (vouchers) that can be used for any legal child care arrangement. Some observers are concerned that subsidies of this form provide no direct incentive to purchase high-quality care and that parents may be too willing to purchase child care of mediocre quality (Blau 2001, ch. 10; Hayes, Palmer, and Zaslow 1990, p. 241). ${ }^{51}$ Subsidies that are disbursed directly to providers, including Head Start, Title I-A, and some CCDF and TXX funds, can be tied more closely to meeting standards that are associated with high quality. Child development advocates push for increased attention to the quality of child care subsidized by the CCDF and other employment-related subsidies. Some would prefer to see an entirely child development-oriented public subsidy system for child care. In contrast, welfare reform advocates concerned mainly with increasing employment focus on the flexibility and freedom of choice provided by vouchers that are not tied to quality standards.

\subsubsection{Reform Options}

Proposals for reform of child care and early education subsidy programs fall into two broad groups. One set of proposals, mainly by economists, is focused on the low-income population, emphasizes freedom of choice for parents, and is typically although not always more employment-oriented than child development-oriented. These include Barnett (1993b), Blau (2001), Helburn and Bergmann (2002), Robins (1990), and Walker (1996). The other set of proposals is advocated mainly by child development experts and emphasizes universal coverage and supply-side subsidies that are tied closely to the quality of care rather than to employment. Examples include Kagan and Cohen (1996) and Finn-Stevenson and Zigler (1999)..$^{52}$

51. See Besharov and Samari (2000) for a detailed discussion of child care vouchers and the quality of child care.

52. Other authors have discussed general principles for reform of child care policy but have not made specific reform proposals. See Committee for Economic Development (2002); Hayes, Palmer, and Zaslow (1990, ch. 10); Gomby et al. (1996); Kahn and Kamerman (1995); and Vandell and Wolfe (2000). Hayes, Palmer, and Zaslow do offer some specific recommendations, including expansion of Head Start. Gormley (1995) makes a number of child care policy recommendations that are generally similar in style and intent to those of the economists. 
Barnett (1993b) calls for a unified federal child care subsidy program for preschool-age children that would replace all other child care subsidies except Head Start. A baseline subsidy would be available to all families, with a supplemental subsidy for families in which the mother is employed. The subsidy would be universal but would decline in value from $\$ 6,000$ per child plus $\$ 2,000$ if the mother works for the poorest 25 percent of families, to $\$ 3,500$ plus $\$ 4,500$ for the next poorest quarter of families, to $\$ 1,000$ per child plus $\$ 1,000$ if the mother works for the upper half of the family income distribution. The subsidy could take the form of vouchers, contracts, or "credit accounts," the latter envisioned as a child care credit card. Barnett states that his proposal explicitly relies on parents to monitor quality and on the market to respond to increased demand for high-quality care by supplying more such care. He is willing, however, to consider limiting use of the subsidy to child care providers who meet high quality standards ( $\mathrm{p}$. 549). He estimated the cost of his proposal at about $\$ 60$ billion after accounting for elimination of funding for subsidies that would be replaced by his program. The goals of Barnett's proposal are to make high-quality child care affordable for all families and to increase the financial rewards from employment for women. ${ }^{53}$

Blau (2001) proposes a child care subsidy in the form of a voucher that is worth more if higher-quality care is used. For families below the poverty line, the voucher would be worth $\$ 6,000$ per child aged zero to five for care of "excellent" quality, $\$ 4,000$ for care of "good" quality, and $\$ 2,000$ for care of "other" quality. Quality would be determined by accreditation based on the developmental appropriateness of the care offered. The value of the voucher would decline with family income, and families with income over four times the poverty line would be ineligible. The voucher would be worth less for children aged six to twelve, and a family could qualify for vouchers for two children at most. Eligibility for the voucher would not depend on employment; the aim of the subsidy is to improve child development, not encourage employment. The proposed voucher plan would replace all other child care subsidies (including Head Start, which would be integrated into the voucher scheme), at an estimated net annual cost of \$54 billion. ${ }^{54}$

Helburn and Bergmann (2002) propose a subsidy for child care in the form of a voucher that would cover the full cost of child care for families below the poverty line. Families with income above the poverty line would incur a copayment of 20 percent of the excess of family income over the

53. Other elements of his overall strategy to achieve these goals include paid parental leave and support for increased accreditation and professionalization of child care.

54. Other elements of the reform proposed by Blau (2001) include a child allowance, subsidies to providers for the cost of the accreditation process, and an educational campaign to disseminate information about the quality of child care. The cost of these additional elements is not included in the $\$ 54$ billion. 
poverty line. The value of the voucher would be higher if higher-quality child care is used, where quality is based on accreditation or staff qualifications. The voucher could be used only at licensed facilities, including family day care, babysitters, nannies, and relatives if they choose to become licensed. Helburn and Bergmann would also earmark \$2.25 billion per year for activities to improve quality and increase market efficiency. These activities include tightening state regulations and increasing monitoring, standardizing the accreditation system, overhauling the training of care providers, and improving dissemination of information. The total annual cost of the proposed program, after accounting for elimination of existing child care subsidies, is estimated to be $\$ 29$ billion. The proposed program would provide subsidies only for families in which both parents (or the single parent) are employed.

Robins (1990) advocates making the DCTC refundable, more progressive, and more generous. Refundability would make the tax credit of value to low-income families by paying a credit to families with no tax liability. His proposed schedule for the DCTC would have an 80 percent subsidy rate (instead of the current 30 percent) for families with AGI under $\$ 10,000$, phased down gradually to zero for AGI over $\$ 60,000$. He would also increase the maximum amount of child care expenses for which a credit could be claimed from $\$ 2,400$ to $\$ 3,600$ for one child and $\$ 4,800$ to $\$ 7,200$ for two or more. He estimates that making the credit refundable would increase its cost by about 20 percent, and making it more generous and progressive would increase cost by another 55 percent. He also proposes a safety net system of publicly funded day care centers for poor families who cannot take advantage of the DCTC for some reason.

Walker (1996) would replace several existing programs with an unconditional (on employment) child allowance for low-income families, and expanded parental leave. The amount of the child allowance would depend on income and the number and ages of children, but would not require the mother to be employed. The maximum allowance per family would be $\$ 7,600$ for a family with three children under six years old and income less than 150 percent of the poverty line, and about half that level for three children over age six. The subsidy would be cut in half for families with income between 150 percent and 175 percent of the poverty line, and eliminated for income in excess of 175 percent of poverty. The estimated cost of $\$ 45$ billion per year would be financed without raising taxes by eliminating the DCTC, AFDC, all other child care subsidies (except Head Start), and the income tax exemption for children. Eliminating the DCTC and the income tax exemption for children would significantly redistribute benefits from higher- to lower-income families. ${ }^{55}$

55. The other part of Walker's plan is a Parental Leave Account (PLA), funded by an additional payroll tax on employees of 3.5 percent. Parents could draw funds from their PLA to finance a leave from work for up to one year after the birth of a child, with the right to their old job back. 
Finn-Stevenson and Zigler (1999) propose a "Schools of the 21st Century" plan that would use public schools as a setting to provide care for children aged three to five and before and after-school care for children aged six to twelve. ${ }^{56}$ The child care provided in the schools would be of high quality and available to all families regardless of income. By providing child care in schools, Finn-Stevenson and Zigler also hope to professionalize the child care occupation and raise pay for providers. ${ }^{57}$ Child care in the schools would be financed mainly by sliding scale parent fees. They argue that the fee for high-quality child care in the schools need be no higher than the fee for average-quality care in other settings because administrative, occupancy, and utility costs would be absorbed by the school system, leaving only staff and materials costs to be financed by parent fees. Startup costs such as building renovation and expansion would be financed by a combination of federal, state, and local government funding and private foundations. They do not provide estimates of the total cost of their proposal. They suggest that funding come from a variety of sources and mainly be new funding rather than funding reallocated from existing programs (they do propose to reallocate funding for existing pre-K programs). Given the large scope of the program, it seems likely that it would be at least as costly as the Barnett, Blau, and Helburn-Bergmann proposals.

Kagan and Cohen (1996) discuss a "vision" for reinventing the early care and education system in the United States. Their discussion emphasizes the principles of a new system but does not propose a specific program. However, they do make some specific proposals related to licensing. They propose that individual staff who care for children in centers and family day care homes be required to hold a license that can be obtained only by completing a high level of education and training and demonstrating competency. All education and training would be provided in a setting in which academic credit would be earned. They also propose eliminating most existing licensing exemptions, such as those for church-sponsored day care centers in some states and for small family day care homes. They do not provide an estimate of the cost of their proposals, and they propose funding them mainly through new revenue.

The key element of the plans proposed by economists is allowing parental choice of child care. These proposals rely on parents to use subsidies to purchase child care of high quality. The very limited evidence on the price elasticity of demand for child care quality suggests that the elasticity is small (Blau and Hagy 1998; Hagy 1998). Recall that this evidence per-

56. Kahn and Kamerman (1987) also propose a school-based child care system, in less detail than Zigler and Finn-Stevenson.

57. They propose a network of support and outreach services for family day care providers who care for children up to age three, but this is not a major or well-developed part of their proposal. They recognize that their plan does not specifically provide for the care of children before age three, and they state that care for such children can be addressed by paid parental leave. 
tains only to demand for specific attributes of child care such as group size, staff-child ratio, and staff training, not to the process-oriented measures of quality that are the best predictors of child development. There is no direct evidence either for or against the proposition that reducing the effective price of child care to consumers will result in a substantial increase in the quality of care demanded, as measured by child development-oriented instruments such as ECERS. Thus, Barnett, Blau, and Helburn-Bergmann would provide differential reimbursement for high-quality care as an additional incentive. With the exception of Blau and Walker, facilitating employment of mothers is another important goal of the proposals by economists. Allowing parents flexibility in using the subsidies is likely to be helpful in achieving this goal. The child allowances proposed by Blau and Walker allow additional flexibility to parents who wish to use the allowance to purchase child care.

Congress is currently debating reauthorization of PRWORA, including the CCDF. The Bush administration has proposed increasing the work requirement for TANF recipients from thirty to forty hours per week, and this has led to discussion of increasing the level of funding for the CCDF and for giving states increased discretion to shift funds from the TANF block grant to the CCDF. Changes to the key feature of the CCDF subsidy program - vouchers that can be used for any licensed or legally exempt child care arrangement - have not been prominent in the reauthorization debate.

The key features of proposals by developmental psychologists are supplyside subsidies and regulations that are tied to the quality of care. FinnStevenson and Zigler would attempt to ensure high quality by locating child care in schools, where the environment and pay would promote highquality care. Kagan and Cohen are less specific about location and funding issues, but they do emphasize much tougher licensing standards and enforcement as a way of raising the quality of child care. It seems likely that these approaches could be successful in improving the average quality of child care supplied in the United States. However, the emphasis on public supply of child care raises the possibility that problems that are thought to be prevalent in many public schools could affect child care as well. These include absence of incentives for efficient use of resources, resulting in high cost and low productivity. Standard economic analysis of regulations that restrict entry to a service occupation suggest that such regulations will raise the cost of the service, reduce the supply, and increase the "underground" supply of the service. This seems especially likely in the case of family day care, in which the proportion of providers who are unlicensed is estimated to be as high as 90 percent (Hayes, Palmer, and Zaslow 1990, 151).

\subsection{Conclusions}

Child care policy can be used to facilitate employment of mothers and enhance the development of young children. The tension between these al- 
ternative goals ensures that debate and discussion of child care policy issues will continue for the foreseeable future. There is not a consensus on the goals of child care policy or on the means to achieve those goals. This is due in part to conflicting views on the proper role of the government in a domain that was mainly left to families as recently as a generation ago. But it is also a reflection of lack of knowledge about the magnitudes of important parameters that affect the costs and benefits of alternative policies. Economists could make significant contributions to knowledge by careful empirical studies that produce reliable estimates of such parameters. The following issues seem important and well suited to analysis by economists.

- Despite a large number of studies, there is considerable uncertainty about the magnitude of the elasticity of maternal employment with respect to the price of child care. A careful sensitivity analysis along the lines of Mroz's (1987) analysis of the labor supply of married women could be a major contribution to resolving this uncertainty. Many of the studies of this issue include some sensitivity testing, but none have systematically examined all of the main specification and estimation issues using a single data set and a common framework. Research on the price-responsiveness of low-income mothers would be especially useful.

- Consumer demand for quality in child care is not well understood, and additional research could make useful contributions to knowledge. It is important to go beyond studying consumer demand for inputs to the production of quality in child care (group size, etc.). The demand function for quality itself, as measured by ECERS and related instruments, should be estimated. This will require data containing such measures of quality as well as the price and other arguments of the demand function from a representative sample of families. Such data are beginning to be made available in the on going National Institute of Child Health and Human Development's Study of Early Child Care. ${ }^{58}$

- Research on the subsidy take-up decisions of families eligible for child care subsidies would be very useful in order to determine the likely effectiveness of different forms of subsidies. The possibility for research along these lines will be enhanced by including questions on child care subsidies in large nationally representative surveys, as in the Urban Institute's NSAF and recent waves of the SIPP. However, to be useful for this issue, such surveys must explicitly ask respondents who are not receiving a subsidy whether they applied for and were offered a subsidy.

- New research on the supply of child care would be useful. Subsidies to consumers may bid up the price of child care, and it is important to be able to quantify such effects. It would also be useful to examine the 
quality supply decisions of providers, in order to determine how responsive the supply of high-quality care might be to subsidies (Blau and Mocan 2002). Evidence on the supply of child care for lowincome families would be especially useful.

- Finally, despite the fact that a number of welfare-to-work demonstration programs included child care subsidies, it has not been possible to determine the effects of such subsidies because they have almost always been included as part of a package of services provided. A random-assignment demonstration program that focused exclusively on child care could provide valuable information about the impact of child care subsidies on employment of low-income mothers.

\section{Appendix}

\section{Cost-Effectiveness Formulas}

Under the assumptions stated in the text, the cost of the wage subsidy is $(N+\Delta N) h e=h N e\left(w+e \eta_{\mathrm{Nw}}\right) / w$, where $\Delta N$ is the additional employment generated by the subsidy. The gain in hours worked is $h \Delta \mathrm{N}=h N e \eta_{N w} / w$. The cost of the child care subsidy is $P h s+\Delta N h s+\Delta P h s$, where $P$ is the number of working mothers who use paid care. The first term is the cost of subsidizing the paid hours of care that would have been used in the absence of the subsidy; the second term is the cost of subsidizing the paid care hours of the mothers induced to enter the labor force as a result of the subsidy; and the third term is the cost of subsidizing the paid care hours of mothers who would have worked and used unpaid care in the absence of the subsidy and are induced to switch to paid care as a result of the subsidy. This expression can be written as $N h s\left(\theta p-\eta_{N p} s-\theta s \eta_{P p}\right) / p$. The change in hours worked induced by the subsidy is $h \Delta N=-\eta_{N p} h N s / p$.

The figures in table 7A.1 illustrate the cost-effectiveness of wage and price subsidies for alternative values of the elasticities and the proportion of employed mothers who use paid care. The price per hour of child care was fixed at $\$ 2.00$ in all of the calculations, and the wage rate was fixed at $\$ 6.00$. Let $\mathrm{CE}_{e}=\eta_{N w} /\left(w+e \eta_{N w}\right)$ represent the cost-effectiveness of the wage subsidy, and let $\mathrm{CE}_{s}=-\eta_{N p} /\left(p \theta-\eta_{N p} s-\theta s \eta_{P p}\right)$ represent the costeffectiveness of the price subsidy. The last column shows the ratio of the cost effectiveness figures. The subsidies are assumed to be additive, but in order to compare them I specify each subsidy as a given proportion of the wage or price. The calculations use a subsidy rate of 0.2 , so the subsidies are, $e=\$ 1.20$ and $s=\$ 0.40$. Using a higher wage rate increases the ratio $\mathrm{CE}_{s} / \mathrm{CE}_{e}$ by a large amount, and using a higher subsidy rate decreases it by a small amount. 
Cost-Effectiveness of Wage and Price Subsidies (alternative values of the elasticities) and Proportion of Employed Mothers Using Paid Care

\begin{tabular}{lcccccr}
\hline$\eta_{N w}$ & $\eta_{N p}$ & $\eta_{P p}$ & $\theta$ & $\mathrm{CE}_{e}$ & $\mathrm{CE}_{s}$ & $\mathrm{CE}_{s} / \mathrm{CE}_{e}$ \\
\hline 0.2000 & -0.2000 & -0.2000 & 0.4000 & 0.0321 & 0.2193 & 6.8421 \\
0.2000 & -0.2000 & -0.2000 & 0.7000 & 0.0321 & 0.1302 & 4.0625 \\
0.2000 & -0.2000 & -0.5000 & 0.4000 & 0.0321 & 0.2083 & 6.5000 \\
0.2000 & -0.2000 & -0.5000 & 0.7000 & 0.0321 & 0.1235 & 3.8519 \\
0.2000 & -0.5000 & -0.2000 & 0.4000 & 0.0321 & 0.4845 & 15.1163 \\
0.2000 & -0.5000 & -0.2000 & 0.7000 & 0.0321 & 0.3019 & 9.4203 \\
0.2000 & -0.5000 & -0.5000 & 0.4000 & 0.0321 & 0.4630 & 14.4444 \\
0.2000 & -0.5000 & -0.5000 & 0.7000 & 0.0321 & 0.2874 & 8.9655 \\
0.5000 & -0.2000 & -0.2000 & 0.4000 & 0.0758 & 0.2193 & 2.8947 \\
0.5000 & -0.2000 & -0.2000 & 0.7000 & 0.0758 & 0.1302 & 1.7188 \\
0.5000 & -0.2000 & -0.5000 & 0.4000 & 0.0758 & 0.2083 & 2.7500 \\
0.5000 & -0.2000 & -0.5000 & 0.7000 & 0.0758 & 0.1235 & 1.6296 \\
0.5000 & -0.5000 & -0.2000 & 0.4000 & 0.0758 & 0.4845 & 6.3953 \\
0.5000 & -0.5000 & -0.2000 & 0.7000 & 0.0758 & 0.3019 & 3.9855 \\
0.5000 & -0.5000 & -0.5000 & 0.4000 & 0.0758 & 0.4630 & 6.1111 \\
0.5000 & -0.5000 & -0.5000 & 0.7000 & 0.0758 & 0.2874 & 3.7931 \\
\hline
\end{tabular}

If everyone uses paid care then $\theta=1, \eta_{N p}=-\eta_{N w}$, and $\eta_{P p}=0$. Let $s=$ $e$ and use $w^{*}=w-p$ as the base for computing the proportional magnitudes of both subsidies, that is, replace both $w$ and $p$ in the formulas with $w^{*}$. Making the substitutions, the number of additional hours worked per dollar spent on the child subsidy becomes $\eta_{N w} /\left(w^{*}+e \eta_{N w}\right)$. The number of additional hours worked per dollar spent on the wage subsidy is $\eta_{N w} /(w$ $\left.+e \eta_{N w}\right)$. Substitute $w^{*}$ for $w$ and the two formulas are identical.

\section{Subsidy Effects in the Quality Model}

Without loss of generality, let quality be restricted to the unit interval: 0 $\leq q \leq 1$. Since quality has no natural units, any measure of quality can be rescaled to the unit interval, with $\alpha, \beta$, and the child development production function rescaled accordingly. Let $V_{e}$ denote the value of being employed and $V_{n}$ the value of not being employed. The price parameters $\alpha$ and $\beta$ do not affect $V_{n}$, so the employment effects of child care price subsidies depend only on their effects on $V_{e}$. Solve for the demand functions for $\ell$ and $q$ conditional on employment, substitute these functions into the budget constraint and production function, and substitute the latter two equations into the utility function. This defines $V_{e}$. It is then simple to show that $\partial V_{e} / \partial \alpha=-u_{c} h$ and $\partial V_{e} / \partial \beta=-u_{c} h q$, where $u_{c}$ is the marginal utility of consumption and $h$ and $q$ are understood to be the values that satisfy the first order conditions. Since $0 \leq q \leq 1$, this shows that an $\alpha$-subsidy has a (weakly) bigger impact on employment than a $\beta$-subsidy.

Totally differentiating the first-order conditions and solving for the substitution effects of $\alpha$ and $\beta$ on quality yields 


$$
\left.\frac{d q}{d \alpha}\right|_{\bar{u}}=\left.\frac{\lambda D_{\ell q}}{D} \quad \frac{d q}{d \beta}\right|_{\bar{u}}=\frac{\lambda\left(D_{\ell q}+D_{q q}\right)}{D},
$$

where $\lambda>0$ is a multiplier, $D_{\ell q}$ is the minor of element $\ell-q$ of the Bordered Hessian, $D_{q q}$ is the minor of element $q-q$, and $D$ is the determinant of the Bordered Hessian. $D_{\ell q} / D$ is indeterminate in sign but $D_{q q} / D$ is unambiguously negative by the second-order conditions. Thus if $D_{\ell q} / D<0$ then $(d q /$ $d \beta)\left.\right|_{\bar{u}}$ is more negative than $\left.(d q / d \alpha)\right|_{\bar{u}}$ and if $D_{\ell q} / D>0$ then $\left.(d q / d \beta)\right|_{\bar{u}}$ is either negative or is a smaller positive than $\left.(\mathrm{dq} / \mathrm{d} \alpha)\right|_{\bar{u}}$.

\section{References}

Adams, Gina, Karen Schulman, and Nancy Ebb. 1998. Locked doors: States struggling to meet the child care needs of low-income working families. Washington, D.C.: Children's Defense Fund, March.

Adams, Gina, Kathleen Snyder, and Jodi R. Sandfort. 2002. Getting and retaining child care assistance: How policy and practice influence parents' experiences. Urban Institute Occasional Paper no. 55. Washington, D.C.: Urban Institute, March. Available at [http://www.urban.org/UploadedPDF/310451.pdf].

Administration for Children and Families. 1995. Federal child care programs in FY1995. Washington, D.C.: Administration for Children and Families. Available at [http://www.acf.dhhs.gov/programs/ccb/research/1995.htm].

1998. HHS fact sheet: State spending under the child care block grant. Washington, D.C.: Administration for Children and Families, November. Available at [http://www.acf.dhhs.gov/news/press/1998/cc97fund.htm].

1999. Access to child care for low-income working families. Washington,

D.C.: Administration for Children and Families, October. Available at [http:// www.acf.dhhs.gov/programs/ccb/research/ccreport/ccreprt.htm].

. 2000. New statistics show only small percentage of eligible families receive child care help. Washington, D.C.: Administration for Children and Families, December. Available at [http://www.acf.dhhs.gov/news/press/2000/ccstudy.htm]. 2001a. Child Care and Development Fund: Report of state plans for the period 10/01/99 to 9/30/01. Washington, D.C.: Administration for Children and Families. Available at [http://nccic.org/pubs/CCDFStat.pdf].

2001b. Final 1998 state data tables and charts. Washington, D.C.: Administration for Children and Families, February. Available at [http://www.acf.dhhs. gov/programs/ccb/research/archive/98acf800/index.htm].

. 2002. 2002 Head Start fact sheet. Washington, D.C.: Administration for Children and Families. Available at [http://www2.acf.dhhs.gov/programs/hsb/ research/02_hsfs.htm].

. Various years. CCDF final allocations and earmarks. Washington, D.C.: Administration for Children and Families. Available at [http://www.acf.dhhs. gov/programs/ccb/policy1/statlist.htm].

Advisory Committee on Head Start Research and Evaluation. 1999. A recommended framework for studying the impact of Head Start programs. Washington, D.C.: U.S. Department of Health and Human Services, October. Available at [http://www2.acf.dhhs.gov/programs/hsb/hsreac/octrep.htm]. 
Anderson, Patricia M., and Philip B. Levine. 2000. Child care and mothers' employment decisions. In Finding jobs: Work and welfare reform, ed. Rebecca M. Blank and David Card, 420-62. New York: Russell Sage Foundation.

Averett, Susan L., H. Elizabeth Peters, and Donald M. Waldman. 1997. Tax credits, labor supply, and child care. Review of Economics and Statistics 79 (1): 12535.

Barnett, W. Steven. 1992. Benefits of compensatory preschool education. Journal of Human Resources 27 (2): 279-312.

. 1993a. Benefit-cost analysis of preschool education: Findings from a 25year followup. American Journal of Orthopsychiatry 64 (4): 500-08.

1993b. New wine in old bottles: Increasing coherence in early childhood care and education policy. Early Childhood Research Quarterly 8 (4): 519-58.

1995. Long-term effects of early childhood programs on cognitive and school outcomes. The Future of Children 5 (3): 25-50.

Baum, Charles L. 2002. Child care costs and work decisions of low-income mothers. Demography 39 (1): 139-64.

Becker, Gary S., and H. Greg Lewis. 1973. Interaction between quantity and quality of children. Journal of Political Economy 81, part 2 (2): S279-88.

Berger, Mark C., and Dan A. Black. 1992. Child care subsidies, quality of care, and the labor supply of low-income single mothers. Review of Economics and Statistics 74 (4): 635-42.

Bergmann, Barbara. 1996. Saving our children from poverty: What the United States can learn from France. New York: Russell Sage Foundation.

Besharov, Douglas J. 2002. Testimony before the Subcommittee on 21st century competitiveness. Washington, D.C.: U.S. House of Representatives, Committee on Education and the Work Force. 27 February.

Besharov, Douglas J., and Nazanin Samari. 2000. Child-care vouchers and cash payments. In Vouchers and the provision of public services, ed. Eugene Steuerle, Robert Reischauer, Van Doorn Ooms, and George Peterson, 195-223. Washington, D.C.: Brookings Institution Press, Committee for Economic Development, and Urban Institute Press.

Blau, David M. 1997. The production of quality in child care centers. Journal of Human Resources 32 (2): 354-87.

. 1999. The effect of child care characteristics on child development. Journal of Human Resources 34 (4): 786-822.

. 2000. The production of quality in child care centers: Another look. Applied Developmental Science, 4 (3): 136-48.

Foundation.

Blau, David M., and Alison P. Hagy. 1998. The demand for quality in child care. Journal of Political Economy 106 (1): 104-46.

Blau, David M., and H. Naci Mocan. 2002. The supply of quality in child care centers. Review of Economics and Statistics 84 (3): 483-96.

Blau, David M., and Philip K. Robins. 1988. Child care costs and family labor supply. Review of Economics and Statistics 70 (3): 374-81.

. 1991. Child care demand and labor supply of young mothers over time. Demography 28 (3): 333-52.

Blau, David M., and Erdal Tekin. 2002. The determinants and consequences of child care subsidies for single mothers. University of North Carolina-Chapel Hill, Department of Economics. Working paper, January.

Bloom, Dan, Mary Farrell, James J. Kemple, and Nandita Verma. 1999. The family transition program: Implementation and three-year impacts of Florida's ini- 
tial time-limited welfare program. New York: Manpower Demonstration Research Corporation, April.

Bos, Johannes M., Aletha C. Huston, Robert C. Granger, Greg J. Duncan, Thomas W. Brock, and Vonnie C. McCloyd. 1999. New hope for people with low incomes: Two-year results of a program to reduce poverty and reform welfare. New York: Manpower Demonstration Research Corporation, August.

Bowen, Gary L., and Peter A. Neenan. 1993. Does subsidized child care availability promote welfare independence of mothers on AFDC: An experimental analysis. Research on Social Work Practice 3 (4): 363-84.

Campbell, F. A., E. P. Pungello, S. Miller-Johnson, M. Burchinal, and C. T. Ramey. 2001. The development of cognitive and academic abilities: Growth curves from an early childhood educational experiment. Developmental Psychology 37 (2): 231-42.

Campbell, F. A., C. T. Ramey, E. P. Pungello, J. Sparling, and S. Miller-Johnson. 2002. Early childhood education: Young adult outcomes from the Abecedarian Project. Applied Developmental Science 6 (1): 42-57.

Capizzano, Jeffrey, Gina Adams, and Freya Sonenstein. 2000. Child care arrangements for children under five: Variation across states. Assessing the New Federalism Working Paper Series B, no. B-7. Washington, D.C.: Urban Institute, March. Available at [http://www.urban.org/UploadedPDF/anf_b7.pdf].

Chaplin, Duncan D., Philip K. Robins, Sandra L. Hofferth, Douglas A. Wissoker, and Paul Fronstin. 1999. The price elasticity of child care demand: A sensitivity analysis. Washington, D.C.: The Urban Institute. Working Paper.

Chipty, Tasneem, Ann Dryden Witte, Magaly Queralt, and Harriet Griesenger. 1998. What is happening to families receiving cash assistance? A longitudinal study of the early stages of welfare reform. Ohio State University, Department of Economics. Working Paper, November.

Committee for Economic Development. 2002. Preschool for all: Investing in a productive and just society. New York: Committee for Economic Development. Available at [http://www.ced.org/docs/report/report_preschool.pdf].

Connelly, Rachel. 1990. The cost of child care and single mothers: Its effect on labor force participation and AFDC participation. Bowdoin College, Department of Economics. Working Paper.

. 1991. The importance of child care costs to women's decision making. In The economics of child care, ed. David Blau, 87-118. New York: Russell Sage Foundation.

- 1992. The effects of child care costs on married women's labor force participation. Review of Economics and Statistics 74 (1): 83-90.

Connelly, Rachel, and Jean Kimmel. 2000. Marital status and full-time/part-time work status in child care choices. Working Paper no. 99-58. Kalamazoo, Mich.: Upjohn Institute, March. Available at [http://www.upjohninstitute.org/ publications/wp/99-58.pdf].

2001. The effect of child care costs on the labor force participation and welfare recipiency of single mothers: Implications for welfare reform. Working Paper no. 01-69. Kalamazoo, Mich.: Upjohn Institute, March. Available at [http:// www.upjohninstitute.org/publications/wp/01-69.pdf].

Council of Economic Advisors. 1997. The economics of child care. Washington, D.C.: Council of Economic Advisors, December.

Cryer, Debbie, and Margaret Burchinal. 1995. Parents as child care consumers. In Cost, quality, and child outcomes in child care centers: Technical report, ed. Suzanne W. Helburn, 203-20. University of Colorado-Denver, Department of Economics, Center for Research in Economic and Social Policy, June. 
Currie, Janet. 2001. Early childhood intervention programs: What do we know? Journal of Economic Perspectives 15 (2): 213-38.

Currie, Janet, and Duncan Thomas. 1995. Does Head Start make a difference? American Economic Review 85 (3): 341-64.

1999. Does Head Start help Hispanic children? Journal of Public Economics 74 (2): 235-62.

2000. School quality and the longer-term effects of Head Start. Journal of Human Resources 35 (4): 755-74.

Finn-Stevenson, Matia, and Edward Zigler. 1999. Schools of the twenty-first century: Linking child care and education. Boulder, Colo.: Westview Press.

Fronstin, Paul, and Doug Wissoker. 1995. The effects of the availability of low-cost child care on the labor-supply of low-income women. Working Paper. Washington, D.C.: Urban Institute, January.

Fuller, Bruce, Sharon L. Kagan, Gretchen Caspary, Nancy Cohen, Desiree French, Laura Gascue, Africa Hands, James Mensing, Jan McCarthy, Gege Kreischer, Jude Carroll, and Kristen Cool. 2000. Remember the children: Mothers balance work and child care under welfare reform. University of California-Berkeley, Policy Analysis for California Education. Available at [http://pace.berkeley.edu/ remthechild_exsum.pdf].

Fuller, Bruce, Sharon L. Kagan, and Susanna Loeb. 2002. New lives for poor families? Mothers and young children move through welfare reform. The Growing Up in Poverty Project: Wave 2 findings, Technical Report. University of California-Berkeley. Available at [http://www-gse.berkeley.edu/research/PACE/gup_ tech_rpt.pdf].

Fuller, Bruce, Sharon L. Kagan, Jan McCarthy, Gretchen Caspary, Darren Lubotsky, and Laura Gascue. 1999. Who selects formal child care? The role of subsidies as low-income mothers negotiate welfare reform. Paper presented at the Society for Research in Child Development Meeting. April, Albuquerque, New Mexico.

Garces, Eliana, Duncan Thomas, and Janet Currie. 2002. Longer-term effects of Head Start. American Economic Review 92 (4): 999-1012.

Gelbach, Jonah. 2002. Public schooling for young children and maternal labor supply. American Economic Review 92 (1): 307-22.

Giannarelli, Linda, and James Barsimontov. 2000. Child care expenses of America's families. Washington, D.C.: The Urban Institute. Occasional Paper no. 40, December. Available at [http://www.urban.org/UploadedPDF/310028_occa40. pdf].

Gladden, Tricia, and Christopher Taber. 2000. Wage progression among less skilled workers. In Finding jobs: Work and welfare reform, ed. Rebecca M. Blank and David Card, 160-92. New York: Russell Sage Foundation.

Gomby, Deanna S., Nora Krantzler, Mary B. Larner, Carol S. Stevenson, Donna L. Terman, and Richard E. Behrman. 1996. Financing child care: Analysis and recommendations. The Future of Children 6 (2): 5-25. Available at [http://www. futureofchildren.org/information2826/information_show.htm?doc_id=73244].

Gormley, William T. 1995. Everybody's children: Child care as a public problem. Washington, D.C.: The Brookings Institution.

Granger, Robert C., and Rachel Cytron. 1999. Teenage parent programs: A synthesis of the long-term effects of the New Chance demonstration, Ohio's Learning, Earning, and Parenting program, and the Teenage Parent demonstration. Evaluation Review 23 (2): 107-45.

Hagy, Alison P. 1998. The demand for child care quality: An hedonic price theory approach. Journal of Human Resources 33 (3): 683-710. 
Hamilton, Gayle, Thomas Brock, Mary Farrell, Daniel Friedlander, and Kristen Harknett. 1997. The national evaluation of welfare-to-work strategies. Evaluating two welfare-to-work approaches: Two-year findings on the Labor Force Attachment and Human Capital Development programs in three sites. New York: Manpower Demonstration Research Corporation, December.

Hamilton, Gayle, Stephen Freedman, and Sharon M. McGroder. 2000. Do mandatory welfare-to-work programs affect the well-being of children? A synthesis of child research conducted as part of the national evaluation of welfare-to-work. New York: Manpower Demonstration Research Corporation, June.

Han, Wen-Jui, and Jane Waldfogel. 2001. The effect of child care costs on the employment of single and married mothers. Social Science Quarterly 82 (3): 552-68.

Harms, Thelma, and Richard Clifford. 1980. Early childhood environment rating scale. New York: Teachers College Press.

Harms, Thelma, Deborah Cryer, and Richard Clifford. 1990. Infant/toddler environment rating scale. New York: Teachers College Press.

Hayes, Cheryl, John Palmer, and Martha Zaslow. 1990. Who cares for America's children? Child care policy for the 1990s. Washington, D.C.: The National Academy of Sciences Press.

Heckman, James J. 1974. Effects of child-care programs on women's work effort. Journal of Political Economy 82, part 2, (2): S136-63.

1979. Sample selection bias as a specification error. Econometrica 47 (1): $153-62$.

1981. Heterogeneity and state dependence. In Studies in labor markets, ed. Sherwin Rosen, 91-139. Chicago: University of Chicago Press.

Helburn, Suzanne W., ed. 1995. Cost, quality, and child outcomes in child care centers. Technical Report. University of Colorado-Denver, Department of Economics, Center for Research in Economic and Social Policy, June.

Helburn, Suzanne W., and Barbara R. Bergmann. 2002. America's child care problem: The way out. New York: Palgrave, for St. Martin's Press.

Hofferth, Sandra, L., April Brayfield, Sharon Deich, and Pamela Holcomb. 1991. National child care survey, 1990. Report no. 91-5. Washington, D.C.: Urban Institute.

Hotz, V. Joseph, and M. Rebecca Kilburn. 1994. Regulating child care: The effects of state regulations on child care demand and its costs. Santa Monica, Calif.: RAND. Working Paper, August.

Hyslop, Dean. 1999. State dependence, serial correlation, and heterogeneity in intertemporal labor force participation of married women. Econometrica 67 (6): 1255-94.

Internal Revenue Service. 2001. Individual tax statistics, complete report publications, tax year 1999. Available at [http://www.irs.gov/taxstats/display/ 0,,i1\%3D40\%26genericId\%3D16840,00.htm].

Kagan, Sharon L., and Nancy Cohen. 1996. A vision for a quality early care and education system. In Reinventing early care and education: A vision for a quality system, ed. Sharon Kagan and Nancy Cohen, 304-32. San Francisco, Calif.: Jossey-Bass.

Kahn, Alfred J., and Shiela B. Kamerman. 1987. Child care: Facing the hard choices. Dover, Mass.: Auburn House.

1995. Starting right: How America neglects Its youngest children and what we can do about it. New York: Oxford University Press.

Karoly, Lynn A., Peter W. Greenwood, Susan S. Everingham, Jill Houbé, M. Rebecca Kilburn, C. Peter Rydell, Matthew Sanders, and James Chiesa. 1998. Investing in our children: What we know and don't know about the costs and 
benefits of early childhood interventions. Report no. MR-898-TCWF. Santa Monica, Calif.: RAND. Available at [http://www.rand.org/publications/MR/ MR898/].

Kimmel, Jean. 1995. The effectiveness of child care subsidies in encouraging the welfare-to-work transition of low-income single mothers. American Economic Review Papers and Proceedings 85 (2): 271-75.

1998. Child care costs as a barrier to employment for single and married mothers. Review of Economics and Statistics 80 (2): 287-99.

Kisker, Ellen E., Anu Rangarajan, and Kimberly Boller. 1998. Moving into adulthood: Were the impacts of mandatory programs for welfare-dependent teenage parents sustained after the programs ended? Princeton, N.J.: Mathematica Policy Research, February.

Leland, Hayne. 1979. Quacks, lemons, and licensing: A theory of minimum quality standards. Journal of Political Economy 87:1328-46.

Long, Sharon K., Gretchen G. Kirby, Robin Kurka, and Shelley Waters. 1998. Child care assistance under welfare reform: Early responses by the states. Washington, D.C.: Urban Institute. Assessing the New Federalism Occasional Paper no. 15. Available at [http://www.urban.org/UploadedPDF/occa15.pdf].

Love, John M., Peter Z. Schochet, and Alicia L. Meckstroth. 1996. Are they in any real danger? What research does - and doesn't - tell us about child care quality and children's well-being. Princeton, N.J.: Mathematica Policy Research, May.

MaCurdy, Thomas, David Green, and Harry Paarsch. 1990. Assessing empirical approaches for analyzing taxes and labor supply. Journal of Human Resources 25 (3): 415-90.

Maddala, G. S. 1983. Limited and qualitative dependent variables in econometrics. New York: Cambridge University Press.

Magenheim, Ellen B. 1995. Information, prices, and competition in the child care market: What role should government play? In Readings in public policy, ed. J. M. Pogodzinksi, 269-307. Cambridge, Mass.: Blackwell.

Meyers, Marcia K., and Theresa Heintze. 1999. The performance of the child care subsidy system: Target efficiency, coverage adequacy, and equity. Social Service Review 73 (1): 37-64.

Meyers, Marcia K., Theresa Heintze, and Douglas A. Wolf. 2002. Child care subsidies and employment of welfare recipients. Demography 39 (1): 165-80.

Mezey, Jennifer, Rachel Schumacher, Mark H. Greenberg, Joan Lombardi, and John Hutchins. 2002. Unfinished agenda: Child care for low-income families since 1996: Implications for federal and state policy. Policy Brief. Washington, D.C.: Center for Law and Social Policy, March. Available at [http://www.clasp. org/pubs/childcare/child_care.htm].

Michalopoulos, Charles, and Philip K. Robins. 2000. Employment and child care choices in the United States and Canada. Canadian Journal of Economics 33 (2): 435-70.

2002. Employment and child care choices of single parent families in Canada and the United States. Journal of Population Economics 3: 465-95.

Michalopoulos, Charles, Philip K. Robins, and Irwin Garfinkel. 1992. A structural model of labor supply and child care demand. Journal of Human Resources 27 (1): 166-203.

Miller, Cynthia, Virginia Knox, Patricia Auspos, Jo Anna Hunter-Means, and Alan Orenstein. 1997. Making welfare work and work pay: Implementation and 18-month impacts of the Minnesota Family Investment Program. New York: Manpower Demonstration Research Corporation, September.

Mroz, Thomas A. 1987. The sensitivity of an empirical model of married women's 
hours of work to economic and statistical assumptions. Econometrica 55 (3): 765-99.

1999. Discrete factor approximations in simultaneous equation models: Estimating the impact of a dummy endogenous variable on a continuous outcome. Journal of Econometrics 92:233-74.

National Institute of Child Health and Human Development. (NICHD). 2002. The NICHD study of early child care and youth development. Bethesda, Md.: NICHD. Available at [http://public.rti.org/secc/home.cfm].

Pencavel, John. 1986. Labor supply of men: A survey. In Handbook of labor economics, vol. 1, ed. Orley Ashenfelter and Richard Layard, 3-102. Amsterdam: North Holland.

Piecyk, Jessica B., Ann Collins, and J. Lee Kreader. 1999. Patterns and growth of child care voucher use by families connected to cash assistance in Illinois and Maryland. Columbia University, National Center for Children in Poverty, May. Available at [http://cpmcnet.columbia.edu/dept/nccp/ccrp2.pdf].

Pitegoff, Peter, and Lauren Bream. 1997. Child care policy and the Welfare Reform Act. Journal of Affordable Housing and Community Development Law 6 (2): 113 30.

Powell, Lisa M. 1997. The impact of child care costs on the labour supply of married mothers: Evidence from Canada. Canadian Journal of Economics 30 (3): 577-94.

Quint, Janet C., Johannes M. Bos, and Denise F. Polit. 1997. New chance: Final report on a comprehensive program for young mothers in poverty and their children. New York: Manpower Demonstration Research Corporation, October.

Ribar, David. 1992. Child care and the labor supply of married women: Reduced from evidence. Journal of Human Resources 27 (1): 134-65.

. 1995. A structural model of child care and the labor supply of married women. Journal of Labor Economics 13 (3): 558-97.

Riccio, James, Daniel Friedlander, and Stephen Freedman. 1994. GAIN: Benefits, costs, and three-year impacts of a welfare-to-work program. New York: Manpower Demonstration Research Corporation, September.

Robins, Philip K. 1990. Federal financing of child care: Alternative approaches and economic implications. Population and Policy Review 9 (1): 65-90.

. 1991. Child care policy and research: An economist's perspective. In The economics of child care, ed. David Blau, 11-42. New York: Russell Sage Foundation.

Robins, Philip K., and Robert Spiegelman. 1978. An econometric model of the demand for child care. Economic Inquiry 16 (January): 83-94.

Ross, Christine. 1996. State child care assistance programs for low-income families. Washington, D.C.: Mathematica Policy Research, April.

. 1998. Sustaining employment among low-income parents: The role of child care costs and subsidies. Washington, D.C.: Mathematica Policy Research, December.

2002. E-mail to author, based on a forthcoming report on characteristics of state CCDF plans, not yet released to the public, 2 May.

Schumacher, Rachel, and Mark H. Greenberg. 1999. Child care after leaving welfare: Early evidence from state studies. Washington, D.C.: Center for Law and Social Policy, October. Available at [http://www.clasp.org/pubs/childcare/child_ care.htm].

Schumacher, Rachel, Mark H. Greenberg, and Joan Lombardi. 2001. State initiatives to promote early learning. Washington, D.C.: Center for Law and Social 
Policy. Policy Brief, April. Available at [http://www.clasp.org/pubs/childcare/ child_care.htm].

Smith, Kristin. 2002. Who's minding the kids? Child care arrangements, spring 1997. Current Population Reports no. P70-86. Washington, D.C.: U.S. Census Bureau, July. Available at [http://www.census.gov/population/www/socdemo/ childcare.html].

Tekin, Erdal. 2001. The responses of single mothers to welfare and child care subsidy programs under the new Welfare Reform Act. Ph.D. diss., University of North Carolina-Chapel Hill. 2002. Child care subsidies, wages, and employment of single mothers. Georgia State University, Department of Economics. Working Paper, May.

Tunali, Insan. 1986. A general structure for models of double-selection and an application to a joint earnings/migration process with remigration. Research in Labor Economics 8, part B:235-82.

U.S. Advisory Commission on Intergovernmental Relations. 1994. Child care: The need for federal-state-local coordination. Report no. A-128. Washington, D.C.: U.S. Advisory Commission on Intergovernmental Relations, March.

U.S. Bureau of the Census. 1999. Poverty in the United States, 1998. Current Population Report P60-207. Washington, D.C.: U.S. Bureau of the Census, September. Available at [http://www.census.gov/prod/99pubs/p60-207.pdf].

U.S. Department of Agriculture. 2001. Child and adult care food program. [http:// www.fns.usda.gov/cnd/Care/CACFP/cacfpfaqs.htm].

U.S. Department of Education. 1996. Serving preschool children. Washington, D.C.: U.S. Department of Education, April. Available at [http://www.ed.gov/ legislation/ESEA/Title_I/preschoo.html].

U.S. Department of Health and Human Services. 1998. Final rule. Federal Register, 24 July 1998, 39935-98. Available at [http://www.acf.dhhs.gov/programs/ccb/ policy/fr072498.pdf].

. 2001. The economic rationale for investing in children: A focus on child care. Washington, D.C.: U.S. Department of Health and Human Services, Office of the Assistant Secretary for Planning and Evaluation, December.

- Various years. Temporary Assistance for Needy Families (TANF) Program, annual report to Congress. Washington, D.C.: U.S. Department of Health and Human Services. Available at [http://www.acf.dhhs.gov/programs/opre/ director.htm\#annual].

U.S. General Accounting Office. 1994a. Child care subsidies increase the likelihood that low-income mothers will work. Report GAO/HEHS-95-20. Washington, D.C.: U.S. GAO, December. Available at [http://www.gpo.gov].

. 1994b. Early childhood programs: Multiple programs and overlapping target groups. Report GAO/HEHS-95-4FS. Washington, D.C.: U.S. GAO, October. Available at [http://www.gpo.gov].

1995. Welfare to work: Child care assistance limited; welfare reform may expand needs. Report GAO/HEHS-95-220. Washington, D.C.: U.S. GAO, September. Available at [http://www.gpo.gov].

1998. Welfare reform: States' efforts to expand child care programs. Report GAO/HEHS-98-27. Washington, D.C.: U.S. GAO, January. Available at [http:// www.gpo.gov].

1999a. Child care: How do military and civilian center costs compare? Report GAO/HEHS-00-7. Washington, D.C.: U.S. GAO. October. Available at [http://www.gpo.gov].

. 1999b. Early education and care: Early childhood programs and services 
for low-income families. Report GAO/HEHS-00-11. Washington, D.C.: U.S. GAO, November. Available at [http://www.gpo.gov].

2000. Title I preschool education: More children served, but gauging effect on preschool readiness difficult. Report GAO/HEHS-00-171. Washington, D.C.: U.S. GAO, September. Available at [http://www.gpo.gov].

U.S. House of Representatives, Committee on Ways and Means. 1998. 1998 green book. Washington, D.C.: U.S. House of Representatives. Available at [http:// www.access.gpo.gov/congress/wm001.html].

- 2000. 2000 green book. Washington, D.C.: U.S. House of Representatives. Available at [http://www.access.gpo.gov/congress/wm001.html].

Vandell, Deborah Lowe, and Barbara Wolfe. 2000. Child care quality: Does it matter and does it need to be improved? Special Report no. 78. Madison, Wis.: Institute for Research on Poverty, November. Available at [http://www.ssc.wisc. edu/irp/sr/sr78.pdf].

Waldfogel, Jane. 2002. Child care, women's employment, and child outcomes. Journal of Population Economics 3: 527-48.

Walker, James. 1991. Public policy and the supply of child care services. In The economics of child care, ed. David Blau, 51-77. New York: Russell Sage Foundation.

- 1996. Funding child rearing: Child allowance and parental leave. The Future of Children 6 (2): 122-36. Available at [http://www.futureofchildren.org/information2826/information_show.htm?doc_id=73300].

Waller, Margy. 1997. Welfare-to-work and child care: A survey of the ten big states. Washington, D.C.: Progressive Policy Institute, September. Available at [http:// www.ppionline.org/documents/welfare_childcare.pdf]. 